\title{
The Impact of Stratospheric Ozone Recovery on Tropopause Height Trends
}

\author{
SeOK-WoO Son, ${ }^{*}$ Lorenzo M. Polvani, ${ }^{+}$DARryn W. WAugh, ${ }^{\#}$ ThOMAs Birner, ${ }^{@}$ \\ Hideharu Akiyoshi, ${ }^{\&}$ Rolando R. GARCiA,** Andrew GetTElman, $* *$ David A. Plummer, ${ }^{++}$AND \\ EUGENE ROZANOV\#\# \\ * Department of Applied Physics and Applied Mathematics, Columbia University, New York, New York \\ ${ }^{+}$Department of Applied Physics and Applied Mathematics, and Department of Earth and Environmental Sciences, Columbia \\ University, New York, New York \\ \# Department of Earth and Planetary Sciences, The Johns Hopkins University, Baltimore, Maryland \\ ${ }^{\circledR}$ Department of Physics, University of Toronto, Toronto, Ontario, Canada \\ \& National Institute for Environmental Studies, Tsukuba, Japan \\ ** National Center for Atmospheric Research, Boulder, Colorado \\ $+{ }^{+}$Environment Canada, Toronto, Ontario, Canada \\ \#\# Institute for Atmospheric and Climate Sciences/ETH, Zurich, and Physical Meteorological Observatory, World Radiation Center, \\ Davos, Switzerland
}

(Manuscript received 31 August 2007, in final form 30 June 2008)

\begin{abstract}
The evolution of the tropopause in the past, present, and future climate is examined by analyzing a set of long-term integrations with stratosphere-resolving chemistry climate models (CCMs). These CCMs have high vertical resolution near the tropopause, a model top located in the mesosphere or above, and, most important, fully interactive stratospheric chemistry. Using such CCM integrations, it is found that the tropopause pressure (height) will continue to decrease (increase) in the future, but with a trend weaker than that in the recent past. The reduction in the future tropopause trend is shown to be directly associated with stratospheric ozone recovery. A significant ozone recovery occurs in the Southern Hemisphere lower stratosphere of the CCMs, and this leads to a relative warming there that reduces the tropopause trend in the twenty-first century.

The future tropopause trends predicted by the CCMs are considerably smaller than those predicted by the Intergovernmental Panel on Climate Change Fourth Assessment Report (AR4) models, especially in the southern high latitudes. This difference persists even when the CCMs are compared with the subset of the AR4 model integrations for which stratospheric ozone recovery was prescribed. These results suggest that a realistic representation of the stratospheric processes might be important for a reliable estimate of tropopause trends. The implications of these finding for the Southern Hemisphere climate change are also discussed.
\end{abstract}

\section{Introduction}

The tropopause is the boundary between the turbulently mixed troposphere and the stably stratified stratosphere. Its formation and maintenance is primarily attributed to radiative-convective processes (Manabe and Strickler 1964; Held 1982; Thuburn and Craig 2000), but in the extratropics, synoptic-scale ed-

Corresponding author address: Seok-Woo Son, Department of Atmospheric and Oceanic Sciences, McGill University, 805 Sherbrooke Street West, Montreal, QC H3A 2K6, Canada.

E-mail: seok-woo.son@mcgill.ca dies are also known to play an important role (Held 1982; Haynes et al. 2001; Schneider 2004). Beyond theoretical interests, the tropopause has been much studied as an exchange region for mass, moisture, and chemical constituents between the troposphere and the stratosphere. Because slight changes in the moisture and chemical constituent fluxes across the tropopause may lead to significant changes in the global climate, a precise knowledge of the spatial and temporal structure of the tropopause is of much interest (Holton et al. 1995; Hoinka 1998).

Recent studies by Sausen and Santer (2003) and Santer et al. (2003a) suggest that the tropopause might also be used as an indicator of global climate change. A 
number of studies using radiosonde, satellite, reanalysis, and coupled atmosphere-ocean general circulation model (GCM) data show a statistically significant decrease (increase) in the global tropopause pressure (height) over last three decades (Steinbrecht et al. 1998; Randel et al. 2000; Seidel et al. 2001; Santer et al. 2003a,b, 2004; Seidel and Randel 2006). Santer et al. (2003a,b) attributed this trend to human-induced changes in greenhouse gases and stratospheric ozone: the upper-tropospheric (UT) warming associated with increased greenhouse gases and the lower-stratospheric (LS) cooling associated with ozone depletion led to a decrease in tropopause pressure. Extending these results, Sausen and Santer (2003) and Santer et al. (2003b) showed that global tropopause pressure $\left\langle P_{\mathrm{TP}}\right\rangle$ may continue to decrease in the future at a rate comparable to the recent trend.

A significant $\left\langle P_{\mathrm{TP}}\right\rangle$ trend, similar to the one in the reanalyses and the GCM integrations, has been found in radiosonde observations (Seidel et al. 2001; Seidel and Randel 2006). The trend in tropical $P_{\mathrm{TP}}$ is relatively weak but spatially homogeneous. In contrast, the trend in extratropical $P_{\mathrm{TP}}$ is quite strong and localized. Moreover, Seidel and Randel (2006) indicated that this spatial pattern is mostly correlated with LS temperature. The contribution by UT temperature was found to be much weaker than that expected from the GCM integrations, suggesting that the tropopause pressure (or height) may only carry limited information about global warming in the troposphere.

The discrepancy between GCM integrations and radiosonde observations may arise from the UT/LS processes that are insufficiently resolved in the GCMs. Conventional GCMs generally have coarse vertical resolution in the UT/LS region and above, and stratospheric processes are mostly ignored. Because the lowfrequency variability of the tropopause is affected by the stratospheric circulation (Yulaeva et al. 1994; Randel et al. 2000; Wong and Wang 2003) and ozone chemistry (Steinbrecht et al. 1998; Wong and Wang 2003), a poor representation of the stratosphere could significantly affect the spatial and temporal structure of the modeled tropopause. It also makes the future trend of $\left\langle P_{\mathrm{TP}}\right\rangle$, estimated from previous studies, questionable. Because conventional GCMs resolve stratospheric circulations poorly and ignore ozone chemistry, $\left\langle P_{\mathrm{TP}}\right\rangle$ trends simulated by scenario integrations may be unrealistically dominated by tropospheric warming.

In view of these issues and the importance of the $P_{\mathrm{TP}}$ trend for tropospheric circulation changes, the primary goal of this study is to examine the tropopause trends in the past, present, and future using stratosphere-resolv- ing chemistry climate models (CCMs). Such models have good vertical resolution in the stratosphere and employ fully interactive chemistry (Eyring et al. 2006, 2007). One might therefore hope that they would yield better estimates of stratospheric temperature and tropopause trends. As we will show below, the tropopause pressure (height) is found to decrease (increase) continuously from the twentieth to the twenty-first century. Its trend in the future, however, will be significantly weaker than that in the recent past, because of the expected stratospheric ozone recovery associated with the Montreal Protocol. The effect of stratospheric processes on tropopause trends is explicitly demonstrated by comparing the results of the CCMs with those of the Intergovernmental Panel on Climate Change (IPCC) Fourth Assessment Report (AR4) models, in which the stratosphere is poorly resolved and the ozone is prescribed (Randall et al. 2007; Meehl et al. 2007).

This paper is organized as follows. In section 2 we describe the data we have analyzed and the methodology used. In section 3, we examine the tropopause pressure over the globe, tropics, and extratropics separately for the CCM integrations. While the main focus is placed on the twenty-first century, the tropopause in the recent past is also examined and compared with radiosonde observations and reanalysis data. It is found that the CCMs successfully reproduce the recent trends in tropopause pressure, providing credence to the CCMs for estimating the tropopause trend in the future. In section 4, the CCM results are compared with those of the IPCC AR4 model integrations. This comparison reveals the importance of resolving stratospheric processes for studying tropopause and LS temperature trends. Last, implications of our findings to the tropospheric circulation change in the Southern Hemisphere are presented in section 5 .

\section{Data and methodology}

Following previous studies (e.g., Santer et al. 2003a; Seidel and Randel 2006), the tropopause pressure $P_{\mathrm{TP}}$ is defined as the lowest level where the temperature lapse rate is less than $2 \mathrm{~K} \mathrm{~km}^{-1}$ for a depth of more than $2 \mathrm{~km}$. This is the standard definition from the World Meteorological Organization (WMO 1957). Relative to other tropopause definitions, such as the cold-point tropopause in the tropics (Holton et al. 1995; Highwood and Hoskins 1998) or a potential vorticity isosurface in the extratropics (WMO 1986; Hoerling et al. 1991; Hoinka 1998), this so-called lapse-rate tropopause is easily computed and well defined in all latitudes from the equator to the poles. 
We compute the values of $P_{\mathrm{TP}}$ using the algorithm proposed by Reichler et al. (2003). The temperature lapse rate is first calculated in $p^{R / c_{p}}$ coordinates, where $R$ and $c_{p}$ are the gas constant for dry air and the specific heat capacity of dry air at a constant pressure, respectively. Using linear interpolation, one next finds the lowest level at which the lapse rate falls below $2 \mathrm{~K}$ $\mathrm{km}^{-1}$, and then verifies that the average of the lapse rate between that level and all higher levels within $2 \mathrm{~km}$ remains below $2 \mathrm{~K} \mathrm{~km}^{-1}$. If the latter does not hold, one proceeds to the next higher level until the second criterion is satisfied. Although this algorithm may fail to detect $P_{\mathrm{TP}}$ for an isothermal or multistable atmosphere (see Reichler et al. 2003), it identifies $P_{\mathrm{TP}}$ quite well under most conditions. This is particularly true when the algorithm is applied to monthly mean temperature fields, as we do in this study.

The $P_{T P}$ is derived from the monthly mean zonalmean temperature fields on standardized pressure levels. Although the detailed structure of $P_{\mathrm{TP}}$, for example, snapshots in the longitude and latitude domain, may be sensitive to model resolution and calculation procedure, the long-term trend of zonally, latitudinally, and annually averaged $P_{\mathrm{TP}},\left\langle P_{\mathrm{TP}}\right\rangle$, is known to be quite insensitive to them. Using reanalysis data, Santer et al. (2003b) showed that $\left\langle P_{\mathrm{TP}}\right\rangle$ trends derived from monthly mean temperature fields are almost identical to those from 6-h interval temperature fields. Consistent with those results, the $\left\langle P_{\mathrm{TP}}\right\rangle$ trends presented in this study are almost indistinguishable from those directly calculated from daily three-dimensional temperature fields on the model sigma levels (not shown). ${ }^{1}$ The differences are much smaller than the intermodel differences.

The latitudinal integration of $P_{\mathrm{TP}}$ is carried out with an area weight for the whole globe: for the tropics, from $20^{\circ} \mathrm{S}$ to $20^{\circ} \mathrm{N}$, the Southern Hemisphere (SH) extra-

\footnotetext{
${ }^{1}$ We note that this is not true for the high-resolution radiosonde observations. Because the average of the temperature lapse rate between the tropopause and all higher altitudes within $2 \mathrm{~km}$ must remain below $2 \mathrm{~K} \mathrm{~km}^{-1}$, the tropopause height is quite sensitive to the detailed structure of the temperature profiles, such as the presence of a $2 \mathrm{~K} \mathrm{~km}^{-1}$ temperature lapse rate at multiple levels. This problem, however, disappears if one uses monthly mean temperature profiles in which the temperature varies gradually in the vertical and the tropopause is uniquely identified. As such, the long-term trend in monthly mean tropopause height calculated from daily radiosonde observations can be different from that calculated using monthly mean observations. In the reanalysis and GCM data, daily temperature fields already vary smoothly in the vertical because of the relatively coarse resolution. Therefore, the order of time averaging hardly affects the tropopause trends computed from those datasets.
}

tropics, from $90^{\circ} \mathrm{S}$ to $45^{\circ} \mathrm{S}$, and the Northern Hemisphere $(\mathrm{NH})$ extratropics, from $45^{\circ} \mathrm{N}$ to $90^{\circ} \mathrm{N}$. Here, $P_{\mathrm{TP}}$ in the $\mathrm{SH}$ is integrated from the South Pole, although $P_{\mathrm{TP}}$ is often ill-defined inside the $\mathrm{SH}$ polar vortex (Highwood et al. 2000; Reichler et al. 2003; Santer et al. 2004). The noisy fluctuation of $\left\langle P_{\mathrm{TP}}\right\rangle$ at $\mathrm{SH}$ high latitudes is effectively reduced by the area weight, and the resulting time series are qualitatively similar to those integrated northward from $75^{\circ} \mathrm{S}$.

In all cases presented in this study, the linear trend of $\left\langle P_{\mathrm{TP}}\right\rangle$ is calculated by a least squares fit to the annualmean $\left\langle P_{\mathrm{TP}}\right\rangle$ time series. The statistical significance of the trend being nonzero is then evaluated with a onetailed $t$ test. The number of degrees of freedom is estimated from a lag-1 autocorrelation of regression residuals as in Santer et al. [2000, see their Eq. (6)].

Three different datasets are employed in this study: reanalysis data, data from the stratosphere-resolving CCM integrations, and data from the IPCC AR4 model integrations. We describe each one briefly, prior to presenting our results regarding the tropopause.

\section{a. Reanalysis data}

The monthly mean reanalysis data are used to determine how well the CCM integrations are able to capture the trends in $\left\langle P_{\mathrm{TP}}\right\rangle$ over the past two decades. Both the National Centers for Environmental PredictionNational Center for Atmospheric Research (NCEPNCAR) reanalysis and the 40-yr European Centre for Medium-Range Weather Forecasts (ECMWF) ReAnalysis (ERA-40) data are used. They span the time period from January 1960 to December 2005 and from January 1960 to December 2001, respectively.

It should be noted that inhomogeneities are present in time series of reanalysis fields because of the changes in data assimilation. In the southern high latitudes, for instance, agreement between reanalysis fields and observations has been found to be poor prior to the satellite era, particularly in ERA-40 data (Bromwich and Fogt 2004). As such, only data starting after 1979 are considered for the trend and correlation analyses (see also Randel et al. 2000).

\section{b. CCM data}

The CCM integrations analyzed in this study are part of the CCM validation activity (CCMVal) for Stratospheric Processes and Their Role in Climate (SPARC). Details of this project and of the participating models can be found in Eyring et al. (2006, 2007). A total of 13 state-of-the-art CCMs from different modeling groups were involved in this project. Among them, $6 \mathrm{CCMs}$ 
TABLE 1. The CCMs used in this study. In the second column, model resolution is indicated in degrees of longitude and latitude, the number of vertical levels, and the model top. The parenthesized number in the third column denotes the number of realizations used in this study. See Eyring et al. (2006, 2007) for further details.

\begin{tabular}{|c|c|c|c|}
\hline Model & Resolution & Integration length & References \\
\hline $\begin{array}{l}\text { Atmospheric Model with Transport } \\
\text { and Chemistry (AMTRAC) }\end{array}$ & $\begin{array}{l}2.00^{\circ} \times 2.50^{\circ} \times 45 \\
0.0017 \mathrm{hPa}\end{array}$ & $\begin{array}{l}1960-2004(1) \\
1990-2099(3)\end{array}$ & Austin et al. (2006) \\
\hline $\begin{array}{l}\text { Center for Climate System Research } \\
\text { (CCSR)/National Institute for } \\
\text { Environmental Studies (NIES) }\end{array}$ & $\begin{array}{l}2.80^{\circ} \times 2.80^{\circ} \times 34 \\
\quad 0.01 \mathrm{hPa}\end{array}$ & $\begin{array}{l}1980-2004(1) \\
1980-2050(1)\end{array}$ & $\begin{array}{l}\text { Akiyoshi et al. (2004) } \\
\text { Kurokawa et al. (2005) }\end{array}$ \\
\hline CMAM & $\begin{array}{l}3.75^{\circ} \times 3.75^{\circ} \times 71 \\
0.0006 \mathrm{hPa}\end{array}$ & $\begin{array}{l}1960-2004(1) \\
1960-2099(3)\end{array}$ & $\begin{array}{l}\text { Beagley et al. (1997) } \\
\text { de Grandpré et al. (2000) }\end{array}$ \\
\hline GEOSCCM & $\begin{array}{l}2.00^{\circ} \times 2.50^{\circ} \times 55 \\
0.01 \mathrm{hPa}\end{array}$ & $\begin{array}{c}1960-2003(1) \\
1979-2049(2) * 2000-99(1)\end{array}$ & Stolarski et al. (2006) \\
\hline $\begin{array}{l}\text { Solar Climate Ozone Links } \\
\quad \text { (SOCOL) }\end{array}$ & $\begin{array}{l}3.75^{\circ} \times 3.75^{\circ} \times 39 \\
0.01 \mathrm{hPa}\end{array}$ & $\begin{array}{l}1980-2004(1) \\
1980-2050(1)\end{array}$ & $\begin{array}{l}\text { Egorova et al. (2005) } \\
\text { Rozanov et al. (2005) }\end{array}$ \\
\hline WACCM & $\begin{array}{c}4.00^{\circ} \times 5.00^{\circ} \times 66 \\
0.0000045 \mathrm{hPa}\end{array}$ & $\begin{array}{l}1950-2003(3) \\
1980-2050(3)\end{array}$ & Garcia et al. (2007) \\
\hline
\end{tabular}

* The two integrations differ in the specified SST: one uses SST from the Hadley Centre model, the other uses SST from the NCAR CCSM.

which performed long integrations $(50 \mathrm{yr} \text { and more })^{2}$ are used in this study (Table 1).

Although each CCM is based on a different atmospheric GCM and uses a different chemistry scheme (see the references cited in Table 1), all CCMs are forced in a similar way. For the past integrations, all CCMs use the observed sea surface temperature (SST) and volcanic aerosols [except for Goddard Earth Observing System CCM (GEOSCCM) and Whole Atmosphere Community Climate Model (WACCM)]. The surface concentration of greenhouse gases and halogens are based on the Houghton et al. (2001) and WMO/UNEP (2003) reports, respectively.

For the future integrations, the CCMs are essentially identical as for the past integrations, except for the external forcings (Eyring et al. 2007). The forcings are taken from the IPCC Special Report on Emission Scenarios (SRES) greenhouse gases scenario A1B (Nakicenovic and Swart 2000) and the Ab scenario of halogen concentration (WMO/UNEP 2003). The SST is obtained from either IPCC AR4 integrations of the coupled ocean-atmosphere model on which a given $\mathrm{CCM}$ is based, or that from the Met Office's Hadley Centre (Johns et al. 2006). Although the difference in SST may lead to a different climate response, the re-

\footnotetext{
${ }^{2}$ There are two more CCMs that have long-term integrations, the Meteorological Research Institute (MRI) and University of L'Aquila (ULAQ) CCMs. They are not used in this study because of the following reasons. The archived temperature fields of MRI $\mathrm{CCM}$ were interpolated twice, from the model levels to reference pressure levels, and then to CCMVal standard levels. This double interpolation introduces artifacts to $\left\langle P_{\mathrm{TP}}\right\rangle$ trends. ULAQ CCM was discarded in this study because it is based on the quasigeostrophic equations, which may not be valid in the tropics and high latitudes.
}

sulting tropopause trend is only weakly sensitive to the choice of SST, presumably because the long-term trend of SST prescribed in the CCMs is comparable in each integration. For example, two GEOSCCM integrations differing only in the source of SST (integrations from 1979 to 2049 in Table 1) show similar $\left\langle P_{\mathrm{TP}}\right\rangle$ trends. $^{3}$

\section{c. IPCC AR4 data}

To evaluate the effect on the tropopause of stratospheric dynamics and chemistry, the results obtained from the CCM integrations are compared with those from the IPCC AR4 past climate (20C3M) and future SRES A1B scenario integrations (hereafter AR4), available at the Program for Climate Model Diagnosis and Intercomparison (PCMDI) archive. Details of the participating models can be found in Randall et al. (2007, see their Table 8.1) and Meehl et al. (2007, see their Table 10.1). A total of 18 such model integrations, which have temperature data at least up to $70 \mathrm{hPa}$, are used in this study: Bjerknes Centre for Climate Research (BCCR) Climate Model, version 2.0 (BCM2.0),

\footnotetext{
${ }^{3}$ The global $\left\langle P_{\mathrm{TP}}\right\rangle$ in the integration with the Hadley Centre SST is on average approximately $2 \mathrm{hPa}$ higher than that in the integration with the NCAR CCSM SST. This results from the fact that the Hadley Centre SST is systematically colder than the CCSM SST. In terms of the radiative-convective equilibrium processes, the colder surface temperature leads to the lower tropopause height or higher tropopause pressure (e.g., Thuburn and Craig 2000). Nonetheless, the two integrations show similar trends in $\left\langle P_{\mathrm{TP}}\right\rangle$, possibly because of qualitatively similar trends in the two SSTs. For instance, the global $\left\langle P_{\mathrm{TP}}\right\rangle$ trend between 2000 and 2049 in the integration with the Hadley Centre SST is $-0.49 \mathrm{hPa}$ decade $^{-1}$ whereas that in the integration with the CCSM SST is $-0.72 \mathrm{hPa}$ decade $^{-1}$. The difference between the two is much smaller than the difference among CCMs.
} 
Community Climate System Model, version 3 (CCSM3), Canadian Centre for Climate Modelling and Analysis (CCCma) Coupled General Circulation Model, version 3.1 (CGCM3.1), Centre National de Recherches Météorologiques Coupled Global Climate Model, version 3 (CNRM-CM3), Commonwealth Scientific and Industrial Research Organisation Mark version 3.0 (CSIRO Mk3.0), ECHAM5/Max Planck Institute Ocean Model (MPI-OM), Flexible Global OceanAtmosphere-Land System Model gridpoint version 1.0 (FGOALS-g1.0), Geophysical Fluid Dynamics Laboratory (GFDL) Climate Model version 2.0 (CM2.0), GFDL Climate Model version 2.1 (CM2.1), Goddard Institute for Space Studies (GISS) Atmosphere-Ocean Model (AOM), GISS Model E-H (EH), GISS Model E-R (ER), Institute of Numerical Mathematics Coupled Model, version 3.0 (INM-CM3.0), L'Institut Pierre-Simon Laplace Coupled Model, version 4 (IPSLCM4.0), Model for Interdisciplinary Research on Climate 3.2, medium-resolution version [MIROC3.2(med)], Meteorological Research Institute Coupled General Circulation Model, version 2.3.2a (MRI CGCM2.3.2a), Parallel Climate Model (PCM), and Met Office (UKMO) Hadley Centre Global Environmental Model version 1 (HadGEM1). Although multiple realizations are available for several models, only the first ensemble member is used for each model because the difference between ensemble members was found to be much smaller than the one between models (not shown). Note that, for CCMs, all available ensemble members are used to increase the sample size.

As stated above, the stratosphere is poorly resolved in the AR4 models. The vertical resolution in the LS is coarser than that in the CCMs (Cordero and Forster 2006; Eyring et al. 2006, 2007) and, more importantly, half of the AR4 models do not have time-varying stratospheric ozone for the scenario integrations: these are BCCR-BCM2.0, CGCM3.1, FGOALS-gl.0, GISSAOM, GISS-EH, GISS-ER, INM-CM3.0, IPSL-CM4.0, and MRI-CGCM2.3.2 (see Table 3 of Miller et al. 2006; Table 10.1 of Meehl et al. 2007). For those models, stratospheric ozone is held fixed at present-day values. The other half of the AR4 models prescribes ozone to increase slowly toward the preindustrial value, according to the reduction in halogens. However, the detailed spatial and temporal structure of prescribed ozone in the IPCC AR4 scenario integrations is not well documented, and the ozone fields have not been archived.

The AR4 models also differ from the CCMs in the atmosphere-ocean coupling. The ocean component is fully coupled with the atmosphere in all AR4 models. In contrast, none of the CCMs were integrated with a coupled ocean or sea ice model. However, the comparison between CCMs and AR4 models should still be meaningful, because all CCMs used in this study employed a SST that was derived from a companion coupled atmosphere-ocean model.

\section{The tropopause in the $\mathrm{CCM}$ integrations}

The time evolution of tropopause pressure $\left\langle P_{\mathrm{TP}}\right\rangle$ for the past and future from CCM integrations is presented in Fig. 1. To emphasize the trend, time series of $\left\langle P_{\mathrm{TP}}\right\rangle$ are smoothed with an 11-yr running mean average and then subtracted from the reference value at year 2000, which is the average from 1995 to 2005 . Because of the relatively short time series, $\left\langle P_{\mathrm{TP}}\right\rangle$ in the ERA-40 data is set equal to that in the NCEP-NCAR reanalysis data at 1996 instead of zero at 2000.

In Fig. 1 , it is seen that global $\left\langle P_{\mathrm{TP}}\right\rangle$ decreases continuously from the twentieth to the twenty-first century. The details on this trend are first described for the past climate. Discussion of the future $\left\langle P_{\mathrm{TP}}\right\rangle$ trend and its relationship with temperature and ozone follows.

\section{a. Past (1960-99)}

All CCMs successfully reproduce the recent trend in $\left\langle P_{\mathrm{TP}}\right\rangle$. Consistent with both NCEP-NCAR and ERA40 data, the global $\left\langle P_{\mathrm{TP}}\right\rangle$ decreases slowly in the 1960s and 1970s, and more rapidly thereafter (Fig. 1a). The evolution of $\left\langle P_{\mathrm{TP}}\right\rangle$ for each latitudinal band is also well captured (Figs. 1b-d). Note that the abrupt change in $\mathrm{SH}\left\langle P_{\mathrm{TP}}\right\rangle$ in ERA-40 around 1970s (thick light blue line in Fig. 1c) is to a large degree an artifact of the reanalysis. Bromwich and Fogt (2004) have shown that, prior to the satellite era, the agreement between ERA-40 data and observations is very poor in the SH high latitudes.

The linear trends of $\left\langle P_{\mathrm{TP}}\right\rangle$ for the recent past over the period of 1979-99 are summarized in Table 2. It is found that the global $\left\langle P_{\mathrm{TP}}\right\rangle$ decreases at a rate of $-1.53 \pm 0.42 \mathrm{hPa}$ decade $^{-1}$ in the CCM integrations. This value is comparable to that in the NCEP-NCAR reanalysis data $\left(-1.67 \mathrm{hPa}\right.$ decade $\left.^{-1}\right)$ and radiosonde observations $\left[-1.7 \pm 0.6 \mathrm{hPa}\right.$ decade $^{-1}$ between 1980 and 2004 (Seidel and Randel 2006)], but is somewhat smaller than the one in the ERA-40 data $(-2.22 \mathrm{hPa}$ decade $\left.^{-1}\right)$.

The $\left\langle P_{\mathrm{TP}}\right\rangle$ trend in the AR4 past climate integrations $(20 \mathrm{C} 3 \mathrm{M})$ is also presented in Table 2 (last row): the global $\left\langle P_{\mathrm{TP}}\right\rangle$ decreases at a rate of $-1.03 \pm 0.50 \mathrm{hPa}$ decade $^{-1}$. This value is smaller than that found in radiosonde observations, reanalysis data, and CCM integrations. The underestimate is likely due to unrealistically weak LS cooling in those models (see Fig. 8 of 
(a) globe $(90 \mathrm{~S}-90 \mathrm{~N})$

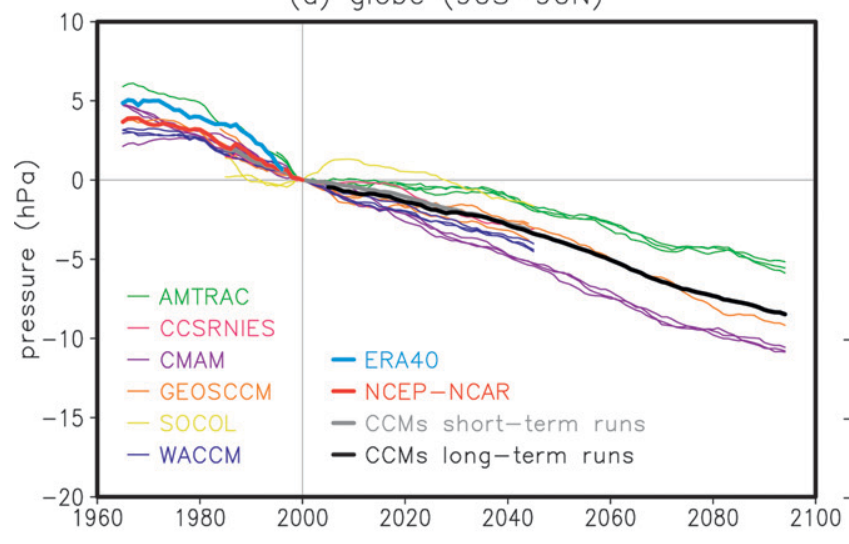

(c) $\mathrm{SH}(90 \mathrm{~S}-45 \mathrm{~S})$

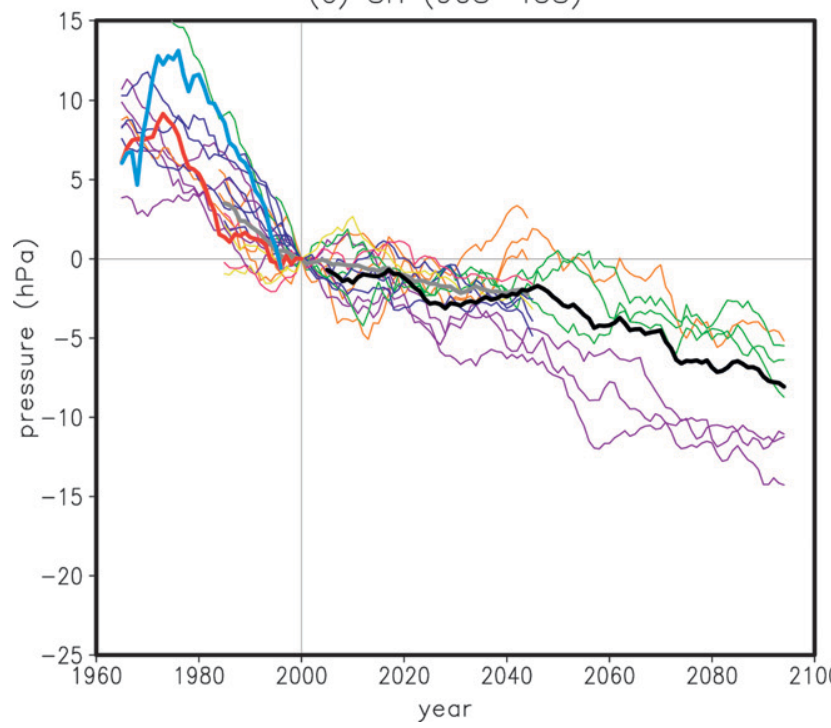

(b) tropics $(20 S-20 N)$

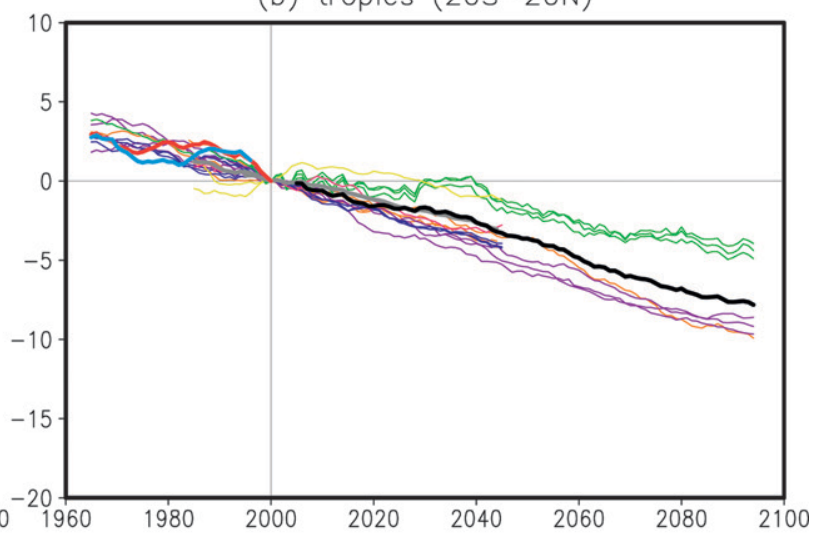

(d) $\mathrm{NH}(45 \mathrm{~N}-90 \mathrm{~N})$

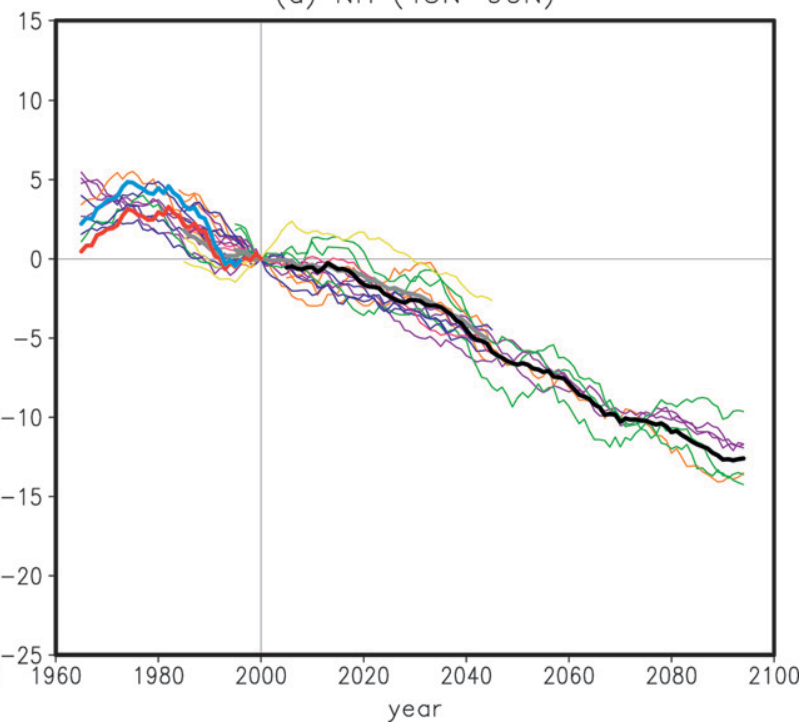

FIG. 1. Time evolution of $\left\langle P_{\mathrm{TP}}\right\rangle$ anomaly for the (a) whole globe, (b) tropics, (c) SH extratropics, and (d) NH extratropics. The anomaly is defined as the dev from the reference value at year 2000 after applying 11-yr running mean average. The thick red and light blue lines, respectively, denote the $\left\langle P_{\mathrm{TP}}\right\rangle$ anomaly for NCEP-NCAR reanalysis and ERA-40 data. The thick gray and black lines denote the multimodel mean $\left\langle P_{\mathrm{TP}}\right\rangle$ anomaly for all CCM integrations and three long-term integrations, respectively.

Cordero and Forster 2006). As discussed in Cordero and Forster (2006), several 20C3M integrations use no ozone depletion (BCCR-BCM2.0, CGCM3.1, GISSAOM, FGOALS-g1.0, INM-CM3.0, IPSL-CM4.0, and MRI-CGCM2.3.2); these models also do not have ozone recovery in the future climate simulations. Furthermore, even models that do include ozone depletion show very weak cooling in the LS (CNRM-CM3, among the models used in this study). This suggests that AR4 past climate integrations should be used with caution when examining $\left\langle P_{\mathrm{TP}}\right\rangle$ and LS temperature trends.

\section{b. Current and future (2000-99)}

The global $\left\langle P_{\mathrm{TP}}\right\rangle$ is predicted by the CCMs to decrease continuously in the future (Fig. 1a). However, its trend is substantially weaker than that in the recent past, particularly in the first half of the twenty-first century. If one defines the significance of the trend difference between any two time series as a nonoverlapping of two trends within one standard deviation, the global $\left\langle P_{\mathrm{TP}}\right\rangle$ trend in the early twenty-first century, $-0.76 \pm$ $0.25 \mathrm{hPa}$ decade $^{-1}$ (Table 3), is significantly different from that in the recent past, $-1.53 \pm 0.42 \mathrm{hPa}$ decade $^{-1}$ (Table 2). This result is noticeably different from the one in previous studies (Sausen and Santer 2003; Santer et al. 2003b) and the AR4 model integrations, which have predicted essentially no change in $\left\langle P_{\mathrm{TP}}\right\rangle$ trends from the twentieth to twenty-first centuries (cf. the bottom rows in Tables 2 and 3). The decreasing trend in $\left\langle P_{\mathrm{TP}}\right\rangle$ becomes somewhat stronger in the last half of the 
TABLE 2. Decadal trend (hPa decade ${ }^{-1}$ ) of $\left\langle P_{\mathrm{TP}}\right\rangle$ between 1979 and 1999 in radiosonde observations, reanalysis data, CCM past climate integrations, and IPCC AR4 20C3M integrations. When multiple realizations are available in CCMs, the trend is averaged after calculating individual trends. One, two, and three asterisks correspond to the trend that is significantly different from zero at the $90 \%$, $95 \%$, and $99 \%$ confidence levels, respectively. The multimodel mean and std dev for the CCM and AR4 20C3M integrations are given in the bottom two rows.

\begin{tabular}{|c|c|c|c|c|}
\hline Data (1979-99) & Globe $\left(90^{\circ} \mathrm{S}-90^{\circ} \mathrm{N}\right)$ & Tropics $\left(20^{\circ} \mathrm{S}-20^{\circ} \mathrm{N}\right)$ & $\mathrm{SH}\left(90^{\circ}-45^{\circ} \mathrm{S}\right)$ & $\mathrm{NH}\left(45^{\circ}-90^{\circ} \mathrm{N}\right)$ \\
\hline Radiosonde observation & $-1.71 \pm 0.6^{\mathrm{a}}$ & $-0.5^{\mathrm{b}}$ & & \\
\hline NCEP-NCAR & $-1.67 * * *$ & -0.88 & $-2.42 * * *$ & $-2.00 * *$ \\
\hline ERA-40 & $-2.22 * * *$ & -0.04 & $-7.43 * * *$ & $-2.93 * * *$ \\
\hline AMTRAC & $-2.41 * *$ & $-0.78^{*}$ & $-6.72 * * *$ & $-2.05 * *$ \\
\hline CCSR/NIES ${ }^{c}$ & -1.53 & $-1.38^{*}$ & -1.49 & $-1.45 * *$ \\
\hline CMAM & $-1.16 * *$ & -0.68 & $-1.38 * *$ & $-1.40 *$ \\
\hline GEOSCCM & $-1.56^{* * *}$ & $-1.12 * * *$ & $-3.14 * *$ & $-2.42 * * *$ \\
\hline $\mathrm{SOCOL}^{\mathrm{c}}$ & $-1.27^{*}$ & -0.40 & $-2.41 * * *$ & $-1.23^{* *}$ \\
\hline WACCM & $-1.25 * * *$ & $-0.55 * *$ & $-3.58 * *$ & $-1.66 * *$ \\
\hline CCM mean & $-1.53 \pm 0.42$ & $-0.82 \pm 0.34$ & $-3.12 \pm 1.80$ & $-1.70 \pm 0.41$ \\
\hline AR4 model mean & $-1.03 \pm 0.50$ & $-0.67 \pm 0.40$ & $-2.22 \pm 1.52$ & $-1.15 \pm 0.98$ \\
\hline
\end{tabular}

${ }^{\text {a }}$ Global $\left\langle P_{\mathrm{TP}}\right\rangle$ trend between 1980 and 2004 (Seidel and Randel 2006).

${ }^{\text {b }}$ Tropical $\left\langle P_{\mathrm{TP}}\right\rangle$ trend, integrated from $15^{\circ} \mathrm{S}$ to $15^{\circ} \mathrm{N}$, between 1978 and 1997 (Seidel et al. 2001).

${ }^{c}$ Trend between 1980 and 1999.

twenty-first century. As such, the global $\left\langle P_{\mathrm{TP}}\right\rangle$ trend for the entire twenty-first century is slightly stronger than that for the first half of the century (Table 4). However, it is still clear that $\left\langle P_{\mathrm{TP}}\right\rangle$ in the future climate decreases more slowly than in the past.

The slow down in the future $\left\langle P_{\mathrm{TP}}\right\rangle$ trend comes mostly from the extratropics. In all CCM integrations, the extratropical $\left\langle P_{\mathrm{TP}}\right\rangle$ in both the $\mathrm{NH}$ and $\mathrm{SH}$ decreases slowly in the future (cf. Tables 2 and 3). This is particularly true in the $\mathrm{SH}$ (see also Fig. 1c). Note that, although CMAM does not show a strong change in $\left\langle P_{\mathrm{TP}}\right\rangle$, its trend is still weaker than that in the past. In the Atmospheric Model with Transport and Chemistry (AMTRAC) runs, the weakening of the global $\left\langle P_{\mathrm{TP}}\right\rangle$ trend is also affected by the tropics.

The simulated trend in $\left\langle P_{\mathrm{TP}}\right\rangle$ in Fig. 1 shows a significant difference among the CCMs. As an example, the $\left\langle P_{\mathrm{TP}}\right\rangle$ trend in AMTRAC is about half of that in CMAM (Fig. 1a). This large intermodel difference is examined in terms of the zonal-mean temperature trend. By definition, the decrease (increase) of the tropopause pressure (height) must be accompanied by UT warming and/or LS cooling across the reference tropopause. This pattern of warming and cooling increases the temperature lapse rate near the tropopause and therefore raises the location of the $2 \mathrm{~K} \mathrm{~km}^{-1}$ lapse rate. The same argument but with an opposite sign is applicable for an increase (decrease) in the tropopause pressure (height). Figure 2 shows the temperature trends for the three CCM integrations that ran to 2100. It can be seen that global $\left\langle P_{\mathrm{TP}}\right\rangle$ decreases in the future owing to the combined effect of tropospheric warming and stratospheric cooling. However, there are substantial differences in LS temperature trend among models, suggesting that the intermodel difference in $\left\langle P_{\mathrm{TP}}\right\rangle$ trends seen in Fig. 1 is caused by different LS temperature trends in each model.

The dependence of $\left\langle P_{\mathrm{TP}}\right\rangle$ trend on the UT/LS temperature trend is further illustrated in Figs. 3a-f, where the relationship between $\left\langle P_{\mathrm{TP}}\right\rangle$, UT temperature, and

TABLE 3. As in Table 2, but for future integrations between 2000 and 2049. For the AR4 models, the earliest possible year is used for the trend calculation when data at year 2000 are not available.

\begin{tabular}{|c|c|c|c|c|}
\hline Data (2000-49) & Globe $\left(90^{\circ} \mathrm{S}-90^{\circ} \mathrm{N}\right)$ & Tropics $\left(20^{\circ} \mathrm{S}-20^{\circ} \mathrm{N}\right)$ & $\mathrm{SH}\left(90^{\circ}-45^{\circ} \mathrm{S}\right)$ & $\mathrm{NH}\left(45^{\circ}-90^{\circ} \mathrm{N}\right)$ \\
\hline AMTRAC & $-0.39 * * *$ & $-0.35^{*}$ & -0.30 & $-1.53 * * *$ \\
\hline CCSR/NIES & $-0.81 * * *$ & $-0.73^{* * *}$ & $-0.60 * *$ & $-1.64 * * *$ \\
\hline CMAM & $-1.19 * * *$ & $-1.13 * * *$ & $-1.19 * *$ & $-1.26 * * *$ \\
\hline GEOSCCM & $-0.59 * * *$ & $-0.82 * * *$ & 0.49 & $-0.93 * *$ \\
\hline SOCOL & $-0.69 * * *$ & $-0.52 * * *$ & $-1.15^{* * *}$ & $-1.12 * * *$ \\
\hline WACCM & $-0.91 * * *$ & $-0.89 * * *$ & $-0.74 * *$ & $-1.12 * * *$ \\
\hline CCM mean & $-0.76 \pm 0.25$ & $-0.74 \pm 0.25$ & $-0.75 \pm 0.33$ & $-1.27 \pm 0.25$ \\
\hline AR4 model mean & $-0.97 \pm 0.34$ & $-0.82 \pm 0.29$ & $-1.00 \pm 0.65$ & $-1.37 \pm 0.41$ \\
\hline
\end{tabular}


TABLE 4. As in Table 2, but for future integrations between 2000 and 2099.

\begin{tabular}{|c|c|c|c|c|}
\hline Data (2000-99) & Globe $\left(90^{\circ} \mathrm{S}-90^{\circ} \mathrm{N}\right)$ & Tropics $\left(20^{\circ} \mathrm{S}-20^{\circ} \mathrm{N}\right)$ & $\mathrm{SH}\left(90^{\circ}-45^{\circ} \mathrm{S}\right)$ & $\mathrm{NH}\left(45^{\circ}-90^{\circ} \mathrm{N}\right)$ \\
\hline AMTRAC & $-0.65 * * *$ & $-0.55 * * *$ & $-0.61 * * *$ & $-1.54 * * *$ \\
\hline CMAM & $-1.18 * * *$ & $1.02 * * *$ & $-1.33 * * *$ & $-1.34 * * *$ \\
\hline GEOSCCM & $-1.02 * * *$ & -1.12 & $-0.47 * * *$ & $-1.57 * * *$ \\
\hline CCM mean & $-0.95 \pm 0.22$ & $-0.90 \pm 0.25$ & $-0.80 \pm 0.38$ & $-1.48 \pm 0.10$ \\
\hline AR4 model mean & $-1.09 \pm 0.32$ & $-0.89 \pm 0.29$ & $-1.30 \pm 0.56$ & $-1.57 \pm 0.53$ \\
\hline
\end{tabular}

LS temperature trends are shown for all CCM integrations. In each model integration, UT and LS are defined by a constant log-pressure distance ${ }^{4}$ of $\ln (100 / 75)$ below and above the tropopause. Although this distance is somewhat arbitrary, the results are qualitatively insensitive to the choice of distance. It is evident that UT temperature trends in all CCM integrations are about the same (Figs. 3a-c) and the intermodel differences in $\left\langle P_{\mathrm{TP}}\right\rangle$ trends are directly associated with differences in LS temperature trends (Figs. 3d-f).

In Figs. 3a-f, it is also noteworthy that UT temperature trends, which are on average about $0.45 \mathrm{~K} \mathrm{day}^{-1}$ in

\footnotetext{
${ }^{4}$ This choice is made for simplicity by the available model levels.
}

the tropics and $0.3 \mathrm{~K} \mathrm{day}^{-1}$ in the extratropics, are generally stronger than LS temperature trends, which are on average about $-0.1 \mathrm{~K} \mathrm{day}^{-1}$ in the tropics and $0.05 \mathrm{~K} \mathrm{day}^{-1}$ in the extratropics for century-long integrations. This stronger temperature trend in the UT provides a hint as to why $\left\langle P_{\mathrm{TP}}\right\rangle$ continues to decrease in the future, because a positive $\left\langle P_{\mathrm{TP}}\right\rangle$ trend is possible only if LS warming is sufficiently strong to reduce the temperature lapse rate near the tropopause (e.g., see open orange circles in Figs. 3b,e). A strong UT warming also suggests that tropopause temperature will increase in the future as can be inferred from Figs. 2a-c (see also Gettelman et al. 2008).

The LS temperature is important not only for understanding intermodel differences in $\left\langle P_{\mathrm{TP}}\right\rangle$ trends but also for understanding the temporal variability of $\left\langle P_{\mathrm{TP}}\right\rangle$. The (a) AMTRAC

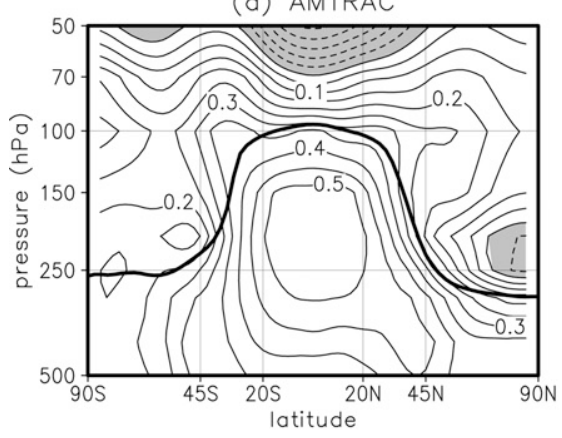

(d) AMTRAC

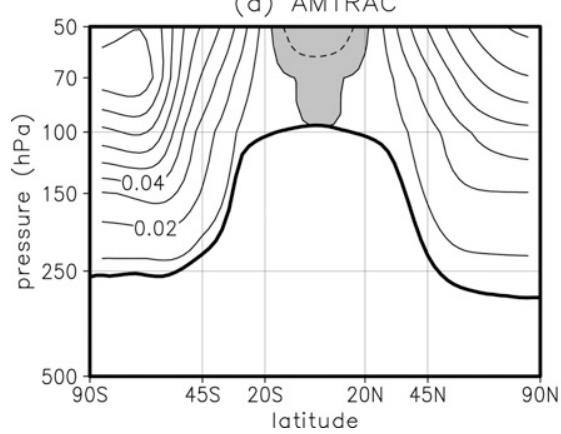

(b) CMAM

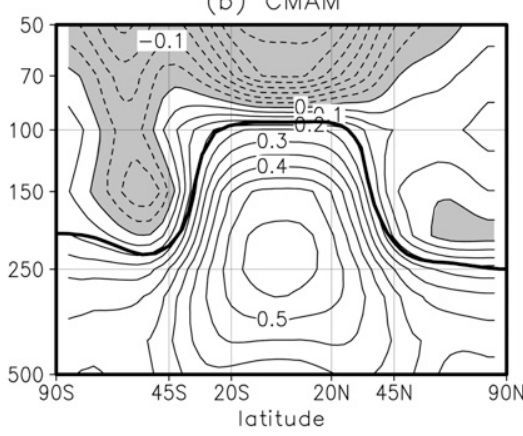

(e) CMAM

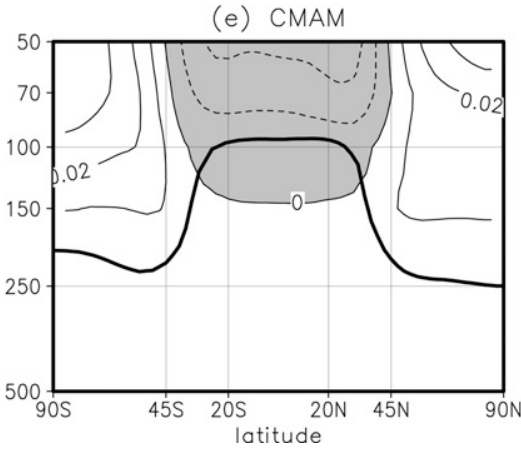

(c) GEOSCCM

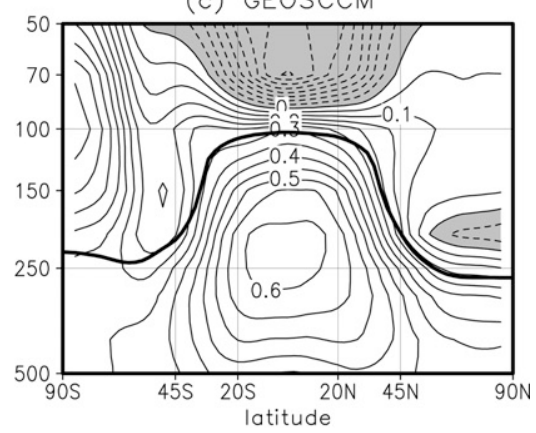

(f) GEOSCCM

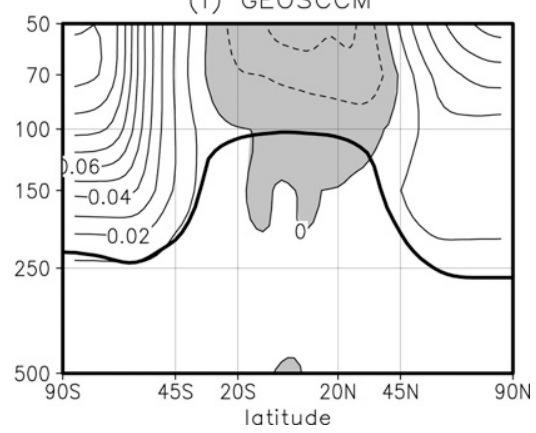

FIG. 2. Ensemble-mean trends of annual-mean zonal-mean (top) temperature and (bottom) ozone for the period of 2000-99: (a), (d) AMTRAC, (b), (e) CMAM, and (c), (f) GEOSCCM integrations. Contour intervals (CIs) are $0.05 \mathrm{~K}^{\text {decade }}{ }^{-1}$ for temperature and 0.005 ppmv decade ${ }^{-1}$ for ozone, and negative values are shaded. Thick solid lines denote the ensemble-mean climatological tropopause for each model. 

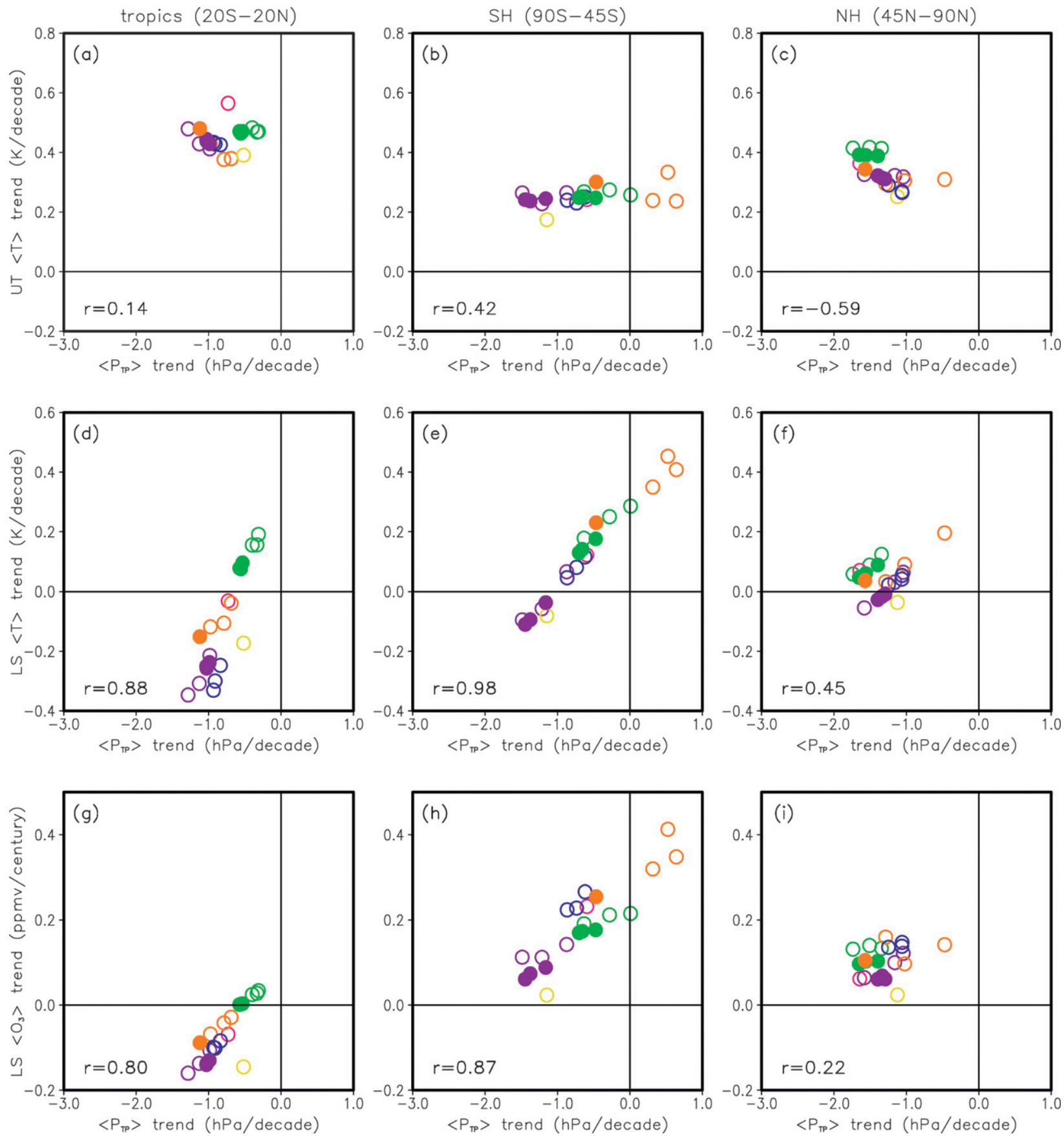

FIG. 3. Relationships among the long-term trends in $\left\langle P_{\mathrm{TP}}\right\rangle$, UT $\langle T\rangle$, LS $\langle T\rangle$, and $\mathrm{LS}\left\langle\mathrm{O}_{3}\right\rangle$ for the (left) tropics, (center) SH extratropics, and (right) NH extratropics. See the text for the definition of UT and LS. Open and filled circles, respectively, denote trends for the period of 2000-49 and those of 2000-99. Color code is same to the one in Fig. 1. Numbers at the left-bottom corner of each panel are correlation coefficients between the two variables in that panel. They are calculated only for open circles, and indicated in black when statistically significant at the $99 \%$ confidence level, and in gray otherwise.

effect of LS temperature to $\left\langle P_{\mathrm{TP}}\right\rangle$ variability is examined by considering the temperature lapse rate near the tropopause $\left(\Gamma_{\mathrm{TP}}\right)$. One may expect that, although somewhat sensitive to the vertical structure of the tempera- ture profile, $\left\langle P_{\mathrm{TP}}\right\rangle$ would decrease as $\left\langle\Gamma_{\mathrm{TP}}\right\rangle$ increases via UT warming and/or LS cooling (Santer et al. 2003b, 2004). For instance, UT warming increases the temperature lapse rate near the tropopause, pushing the 
location where $\Gamma=2 \mathrm{~K} \mathrm{~km}^{-1}$ upward. Likewise, LS cooling increases the temperature lapse rate near the tropopause, also pushing the location where $\Gamma=2 \mathrm{~K}$ $\mathrm{km}^{-1}$ upward (see also Fig. 4 of Son et al. 2007).

The quantity $\left\langle\Gamma_{\mathrm{TP}}\right\rangle$ can be decomposed into the contributions from the UT $\left(\left\langle\Gamma_{\mathrm{TP}, \mathrm{UT}}\right\rangle\right)$ and the $\mathrm{LS}\left(\left\langle\Gamma_{\mathrm{TP}, \mathrm{LS}}\right\rangle\right)$ as follows:

$$
\Gamma_{\mathrm{TP}}=\Gamma_{\mathrm{TP}, \mathrm{UT}}+\Gamma_{\mathrm{TP}, \mathrm{LS}},
$$

where

$$
\begin{aligned}
\Gamma_{\mathrm{TP}, \mathrm{UT}} & =\frac{g}{R}\left(\frac{\ln \overline{T_{\mathrm{TP}}}-\ln T_{\mathrm{UT}}}{\ln p_{\mathrm{LS}}-\ln p_{\mathrm{UT}}}\right) \quad \text { and } \\
\Gamma_{\mathrm{TP}, \mathrm{LS}} & =\frac{g}{R}\left(\frac{\ln T_{\mathrm{LS}}-\ln \overline{T_{\mathrm{TP}}}}{\ln p_{\mathrm{LS}}-\ln p_{\mathrm{UT}}}\right) .
\end{aligned}
$$

Overbars denote time mean and all other symbols are standard. The subscript TP indicates a location near the tropopause level, which is set to $100 \mathrm{hPa}$ in the tropics and $250 \mathrm{hPa}$ in the extratropics by referring to the climatological tropopause in Fig. 2. The LS and UT are then set to 70 and $150 \mathrm{hPa}$ in the tropics, and 200 and $300 \mathrm{hPa}$ in the extratropics.

The results of this decomposition are illustrated, in Fig. 4, for the GEOSCCM integration. As expected, $\left\langle\Gamma_{\mathrm{TP}}\right\rangle$ (black solid) follows $\left\langle P_{\mathrm{TP}}\right\rangle$ (black dashed) very closely, but with the opposite sign. More interesting is the fact that both UT and LS temperature trends are important in setting the $\left\langle P_{\mathrm{TP}}\right\rangle$ trend. Although the decrease in $\left\langle P_{\mathrm{TP}}\right\rangle$ is dominated by UT warming in the $\mathrm{NH}$ extratropics (Fig. 4c), it is almost equally affected by the LS temperature trend in the tropics and $\mathrm{SH}$ extratropics. Specifically, in the SH extratropics the overall negligible trend in $\left\langle P_{\mathrm{TP}}\right\rangle$ results from the cancellation between LS warming and UT cooling (Fig. 4b).

The key role of the LS in controlling $\left\langle P_{\mathrm{TP}}\right\rangle$ is also seen in the interannual variability. Note that $\left\langle\Gamma_{\mathrm{TP}}\right\rangle$ (and $\left.\left\langle P_{\mathrm{TP}}\right\rangle\right)$ is more closely related to $\left\langle\Gamma_{\mathrm{TP}}, \mathrm{LS}\right\rangle$ than to $\left\langle\Gamma_{T P, U T}\right\rangle$. This is confirmed by calculating the correlation between $\left\langle P_{\mathrm{TP}}\right\rangle$ and temperature anomalies at each pressure level after removing the linear trends. The maximum correlation coefficient, which is greater than 0.9 , is found in the LS: at $50-70 \mathrm{hPa}$ in the tropics and at $170-200 \mathrm{hPa}$ in the extratropics. This is consistent with the findings of Seidel and Randel (2006), and suggests that LS processes are important not only for the longterm trend but also for the interannual variability of $\left\langle P_{\mathrm{TP}}\right\rangle$.

Given the importance of LS temperature on the linear trend, intermodel difference, and interannual vari- ability of $\left\langle P_{\mathrm{TP}}\right\rangle$, it is natural to consider how changes in LS temperature are related to those in stratospheric ozone. Using the same CCM integrations, Eyring et al. (2007) showed that column ozone will rapidly increase in the first half of the twenty-first century (see also Austin et al. 2003). This ozone recovery is stronger in the $\mathrm{SH}$ and the resulting LS warming may reduce the $\left\langle P_{\mathrm{TP}}\right\rangle$ trend there, as seen in Fig. 1c. Figures $2 \mathrm{~d}-\mathrm{f}$ show the long-term trends of ozone concentration for the three CCM integrations that ran to 2100. It can be seen that the overall pattern of ozone trends closely resembles the temperature trends shown in Figs. 2a-c. A relatively small decrease in tropical ozone in AMTRAC (Fig. 2d) is consistent with very weak cooling there (Fig. 2a). Weak ozone recovery in the $\mathrm{SH}$ in Canadian Middle Atmosphere Model (CMAM) (Fig. 2e) is accompanied by a relative cooling there (Fig. 2b). In all CCMs, ozone recovery in the $\mathrm{NH}$ is quantitatively similar, and so are the temperature trends. All of these facts indicate that the intermodel differences in LS temperature change (and $\left\langle P_{\mathrm{TP}}\right\rangle$ trend) are to a large degree associated with stratospheric ozone change. This is further confirmed by relationship between stratospheric ozone and $\left\langle P_{\mathrm{TP}}\right\rangle$ trends shown in Figs. $3 \mathrm{~g}-\mathrm{i}$.

It is important to keep in mind that LS temperature is affected not only by the radiative heating associated with ozone but also by the dynamical heating associated with the stratospheric circulation. It has also been noted that the distribution of ozone itself is strongly affected by the stratospheric circulation, especially in the LS (Ko et al. 1989; Jiang et al. 2007). Figure 5 presents the evolution of LS temperature, $\mathrm{O}_{3}$, and the vertical component of the residual circulation $w^{*}$ [computed using Eq. (3.5.1b) in Andrews et al. (1987)] for the century-long GEOSCCM integration. In the tropics (Fig. 5a) LS cooling is in fact closely related with both the decrease in $\mathrm{O}_{3}$ (radiative cooling) and increase in $w^{*}$ (adiabatic cooling). The detrended correlation of the LS temperature with $\mathrm{O}_{3}$ and $w^{*}$ is about 0.90 and -0.85 , respectively. These high correlations with opposite signs further indicate that the decrease in LS ozone is largely associated with the strengthened tropical upwelling (see also Austin and Li 2006).

Unlike the tropics, LS temperature in the extratropics is primarily controlled by ozone-induced heating (Figs. 5b,c). Balancing the enhanced tropical upwelling (Fig. 5a), $w^{*}$ around $70 \mathrm{hPa}$ shows a strong negative trend in the extratropics, especially in the $\mathrm{NH}$ (not shown). This strengthened downwelling, however, does not reach the tropopause. At $200 \mathrm{hPa}, w^{*}$ shows a positive trend, which in turn leads to an anomalous adiabatic cooling (Figs. 5b,c). Although nonnegligible 
(a) tropics $(20 \mathrm{~S}-20 \mathrm{~N})$

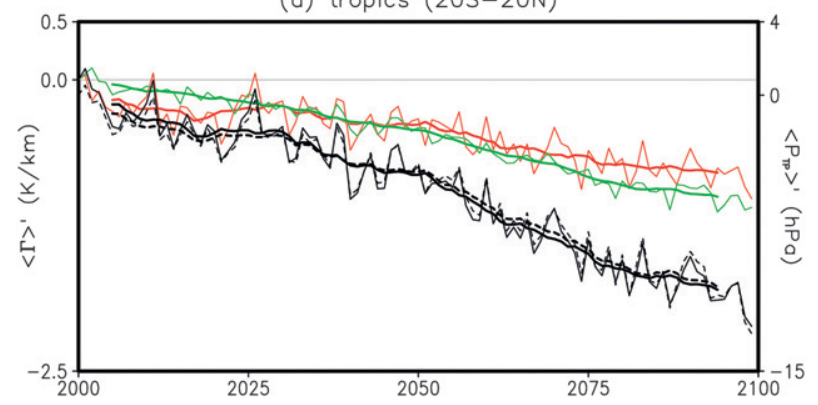

(b) $\mathrm{SH}(90 \mathrm{~S}-45 \mathrm{~S})$

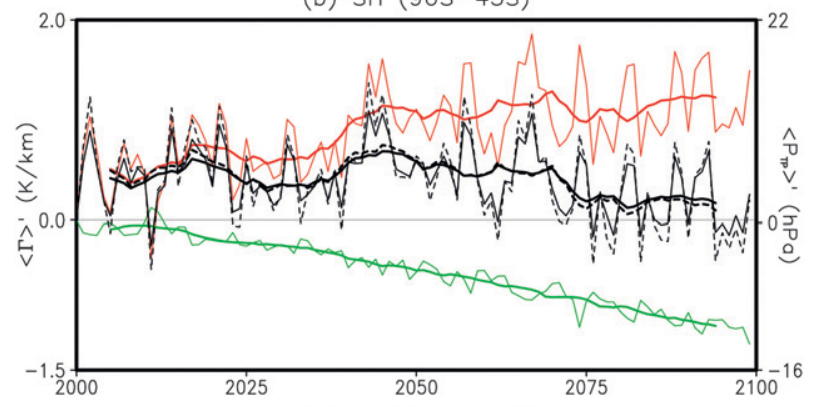

(c) $\mathrm{NH}(45 \mathrm{~N}-90 \mathrm{~N})$

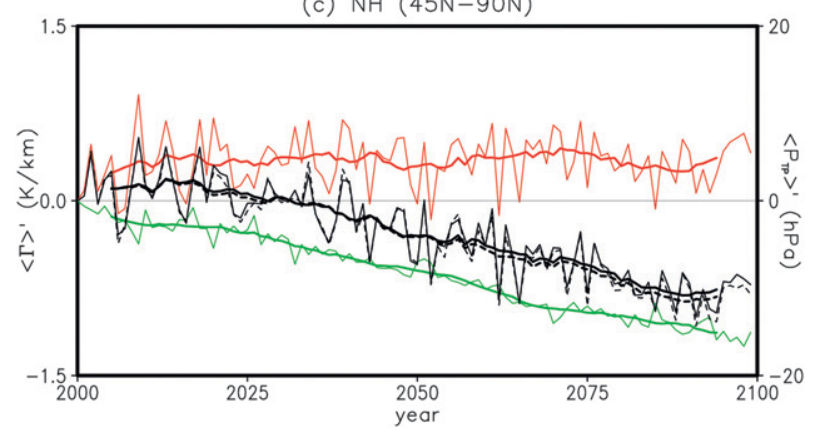

FIG. 4. Time evolution of (black) $\left\langle\Gamma_{\mathrm{TP}}\right\rangle$, (red) $\left\langle\Gamma_{\mathrm{TP}, \mathrm{LS}}\right\rangle$, and (green) $\left\langle\Gamma_{\mathrm{TP}, \mathrm{UT}}\right\rangle$ anomalies for the (a) tropics, (b) SH extratropics, and (c) NH extratropics in the century-long GEOSCCM integration. Superimposed dashed lines show $\left\langle P_{\mathrm{TP}}\right\rangle$ anomaly multiplied by -1 . All quantities are plotted after subtracting the reference values at year 2000. In all panels, the thick lines denote 11-yr running mean averages.

contributions of $w^{*}$ to the LS temperature are found from 2075 to 2099 when $w^{*}$ is relatively strong, the overall trend in LS temperature is more closely related with $\mathrm{O}_{3}$. This suggests that chemistry is more important than dynamics for determining LS temperature trend in the extratropics. Qualitatively similar results are also found in the AMTRAC and CMAM integrations.

\section{Comparison to the IPCC AR4 integrations}

To uncover the precise impact of stratospheric processes on the $\left\langle P_{\mathrm{TP}}\right\rangle$ trend, the above $\mathrm{CCM}$ results are now compared with those from the IPCC AR4 model
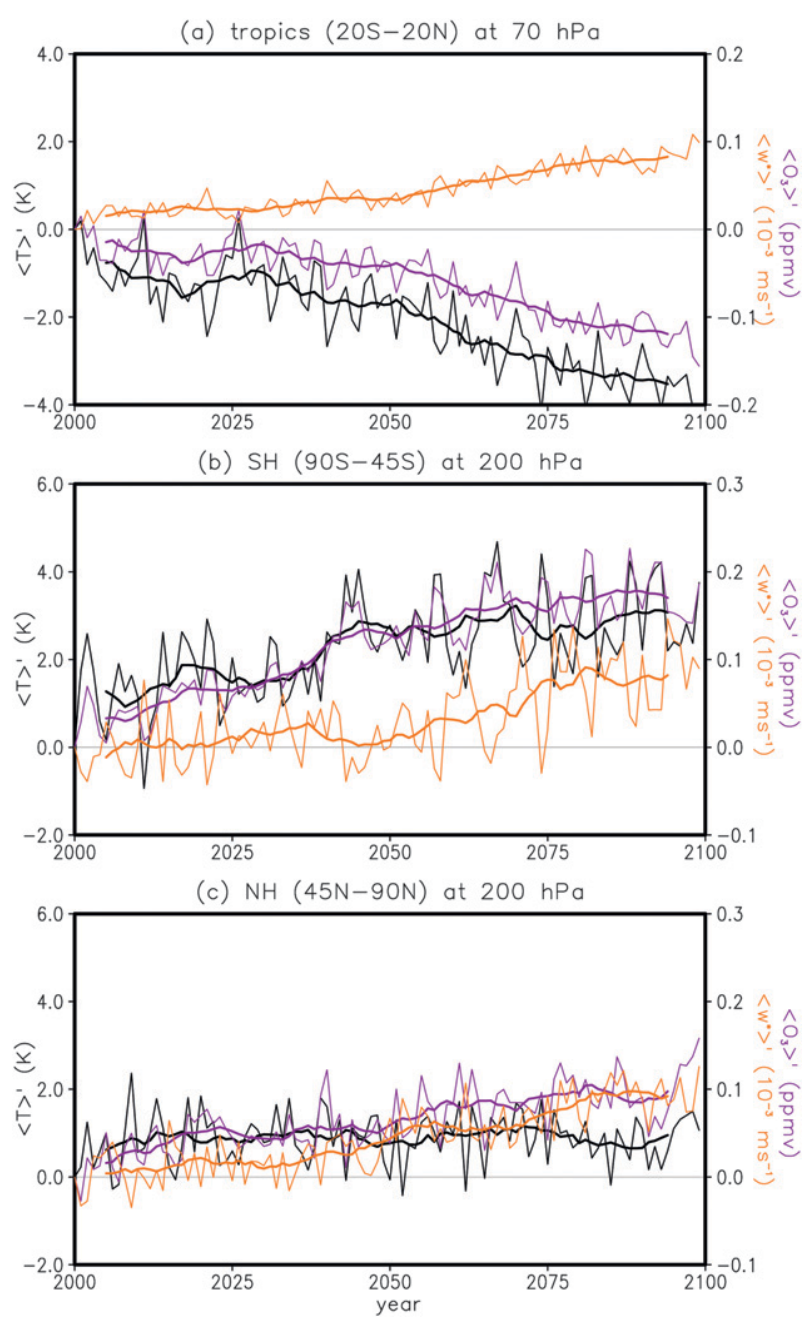

FIG. 5. As in Fig. 4, but for (black) LS $\langle T\rangle$, (purple) $\left(\mathrm{O}_{3}\right)$, and (orange) $\left\langle w^{*}\right\rangle$ anomalies. LS is set to $70 \mathrm{hPa}$ in the tropics and 200 $\mathrm{hPa}$ in the extratropics.

integrations. Here, it should be noted that the number of models used for the comparison is different: 18 AR4 models versus $3 \mathrm{CCMs}$ for the century-long integrations. Because of the relatively small number of CCMs, it is possible that the multimodel mean value for $\mathrm{CCMs}$ could be more biased; hence, comparison with the AR4 models should be treated with caution. With this limitation in mind, both $\left\langle P_{\mathrm{TP}}\right\rangle$ and temperature trends for two sets of model integrations are contrasted, after examining $\left\langle P_{\mathrm{TP}}\right\rangle$ trends in the AR4 model integrations.

Trends in $\left\langle P_{\mathrm{TP}}\right\rangle$ for all AR4 model integrations are summarized in Fig. 6. The multimodel mean values are separately calculated for the integrations with (thick red solid lines) and without (thick red dashed lines) prescribed ozone recovery. It is found that these two subsets of AR4 models predict quantitatively similar global and tropical $\left\langle P_{\mathrm{TP}}\right\rangle$ trends (Figs. 6a,b). Somewhat 
(a) globe $(90 S-90 \mathrm{~N})$

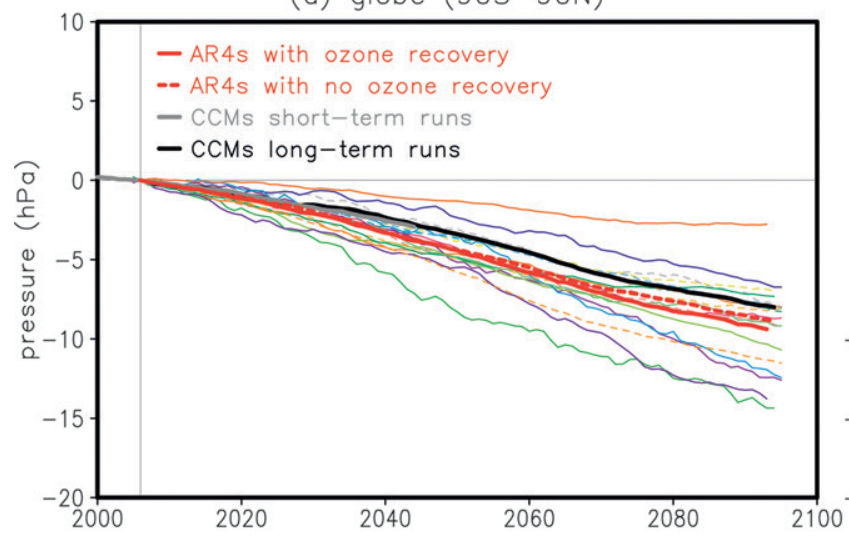

(c) $\mathrm{SH}(90 \mathrm{~S}-45 \mathrm{~S})$

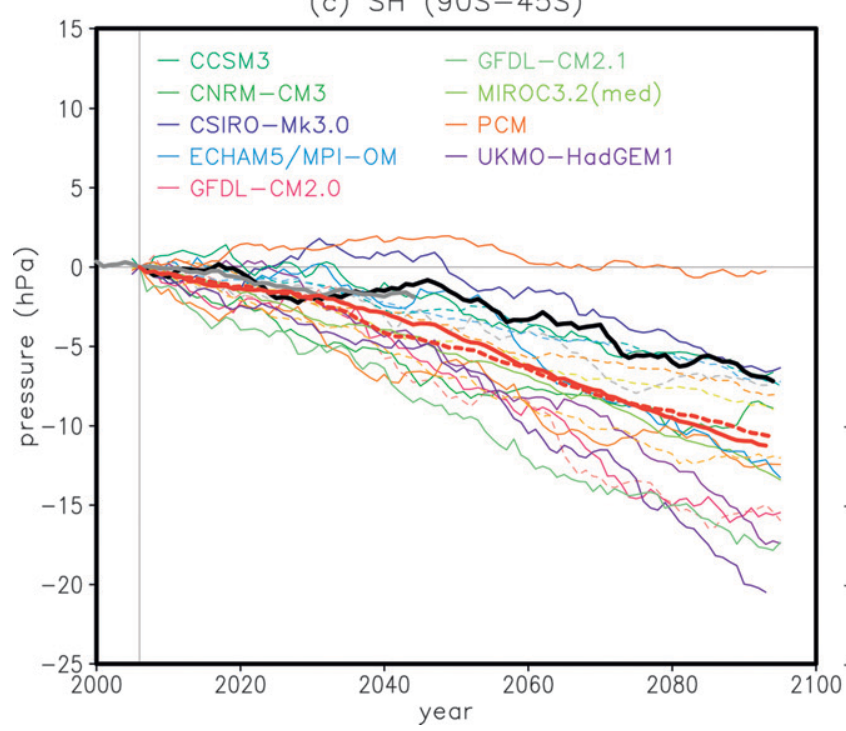

(b) tropics $(20 S-20 N)$

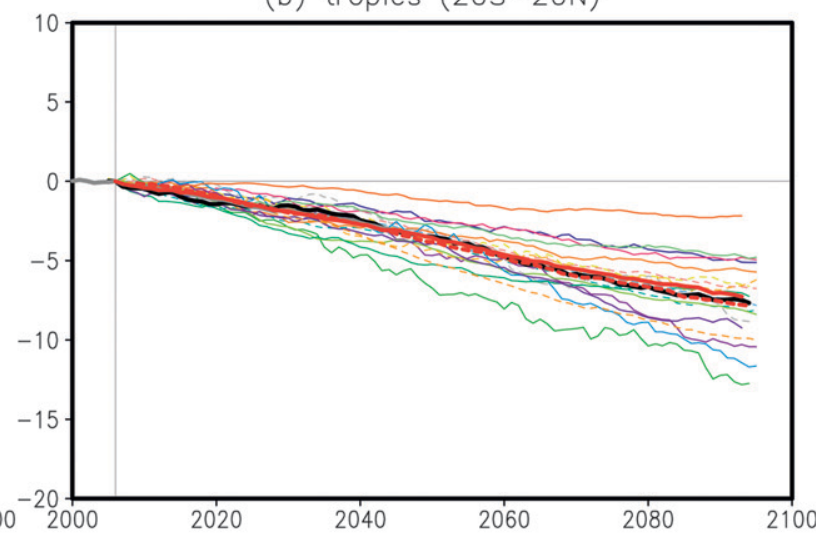

(d) $\mathrm{NH}(45 \mathrm{~N}-90 \mathrm{~N})$

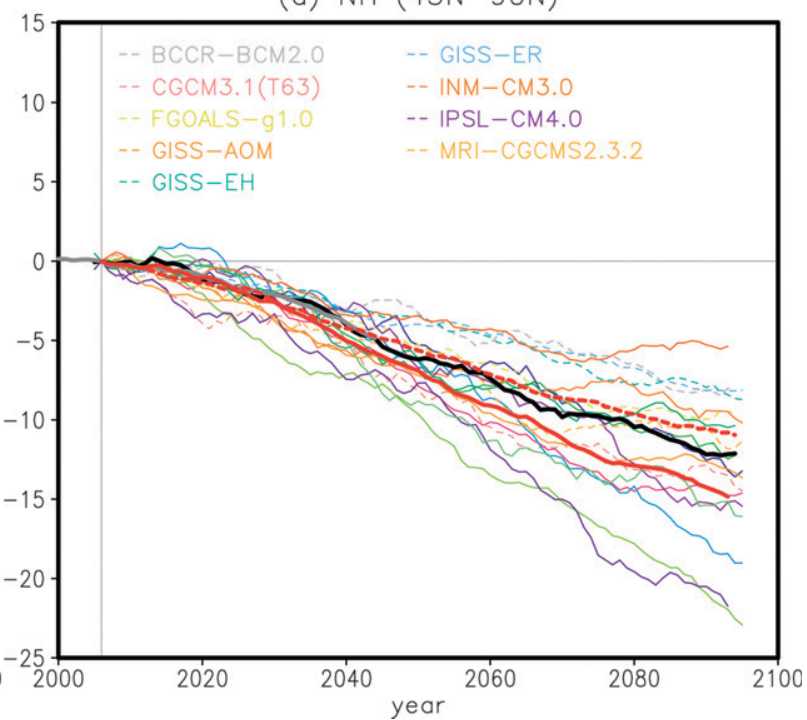

FIG. 6. As in Fig. 1, but for IPCC AR4 model integrations. The reference year is set to 2006. Note that most IPCC AR4 models start integrations from 2001, and the earliest possible year after an 11-yr running mean averaging is thus 2006. The thick solid and dashed red lines denote the multimodel mean $\left\langle P_{\mathrm{TP}}\right\rangle^{\prime}$ for AR4 models with and without prescribed ozone recovery, respectively. The thick black and gray lines are the multimodel mean $\left\langle P_{\mathrm{TP}}\right\rangle$ anomalies in CCMs; they are identical to the thick lines in Fig. 1.

surprisingly, quantitatively similar $\left\langle P_{\mathrm{TP}}\right\rangle$ trends are also found in the $\mathrm{SH}$, where prescribed ozone recovery is expected to result in weaker $\left\langle P_{\mathrm{TP}}\right\rangle$ trends (Fig. 6c). A substantial difference in $\left\langle P_{\mathrm{TP}}\right\rangle$ trends is instead found in the NH (Fig. 6d). This counterintuitive result, along with little difference between the past and future $\left\langle P_{\mathrm{TP}}\right\rangle$ trends from the past $\left\langle P_{\mathrm{TP}}\right\rangle$ trends (cf. the bottom rows in Tables 2-4), suggests that $\left\langle P_{\mathrm{TP}}\right\rangle \mathrm{s}$ in the AR4 models do not properly account for climate change in the stratosphere. As such, $\left\langle P_{\mathrm{TP}}\right\rangle$ trends derived from the AR4 models may not be reliable for quantifying a global climate change.

The counterintuitive sensitivities of the extratropical $\left\langle P_{\mathrm{TP}}\right\rangle$ trends to the prescribed ozone recovery in Figs. $6 \mathrm{c}, \mathrm{d}$ are largely caused by UT temperature trends, which vary widely among AR4 models. Figure 7 shows the dependence of $\left\langle P_{\mathrm{TP}}\right\rangle$ trends on the UT/LS temperature trends for all AR4 model integrations. In the SH, LS cooling is weaker in the ozone recovery cases, presumably because of ozone-induced warming (cf. filled and open circles in Fig. 7e). Relatively stronger warming however is also found in the UT (Fig. 7b), suggesting that ozone-induced warming in the AR4 model integrations is quite broad in the vertical (see also Fig. $8 \mathrm{c}$ ). This broad warming results in very small changes in temperature lapse rate near the tropopause, causing a negligible difference in $\left\langle P_{\mathrm{TP}}\right\rangle$ trends between the two model subsets. The strong sensitivity of the $\mathrm{NH}\left\langle P_{\mathrm{TP}}\right\rangle$ in Fig. $6 \mathrm{~d}$ is also associated with UT temperature trends: while LS temperature trends are comparable in all 

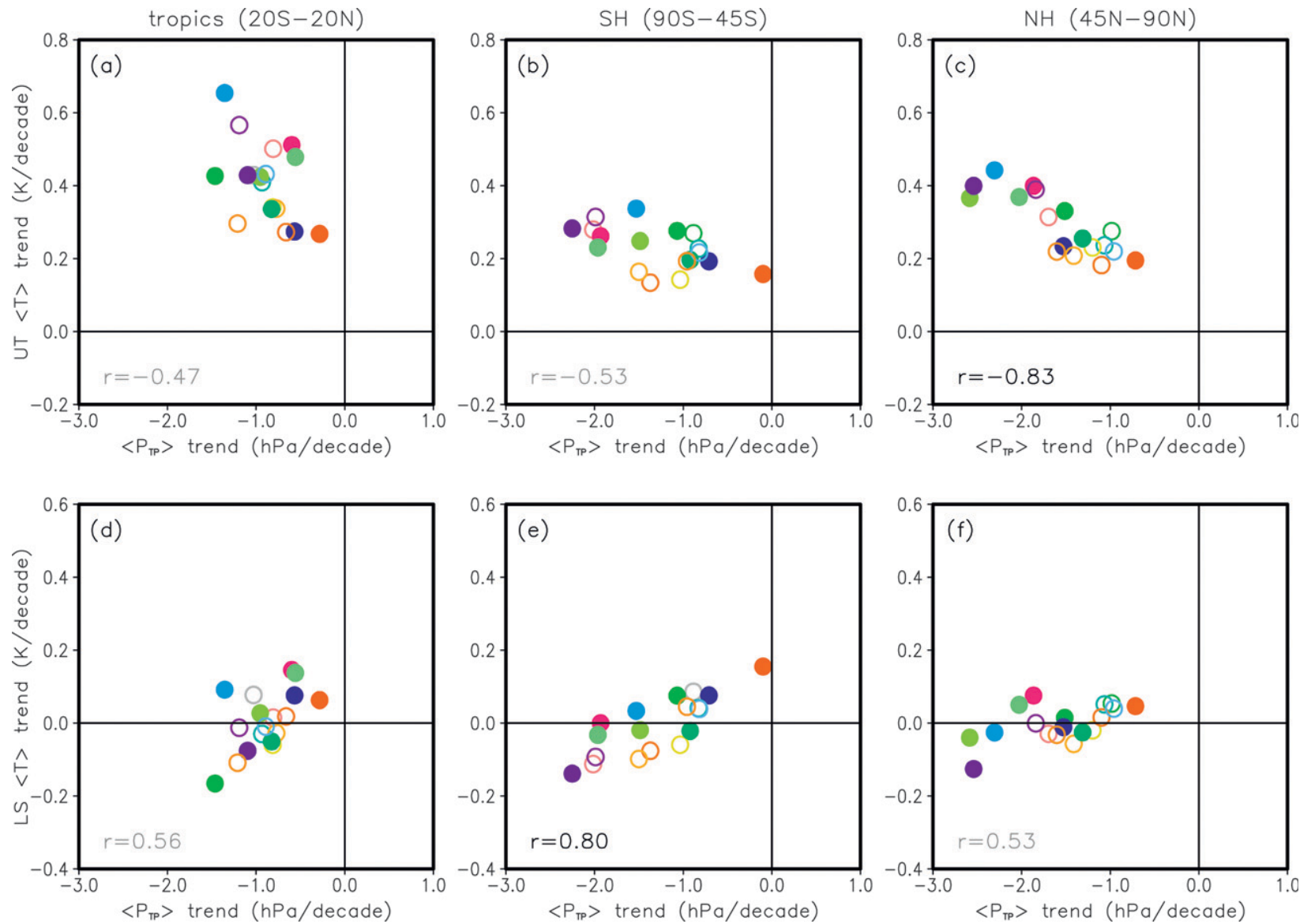

FIG. 7. As in Fig. 3, but for IPCC AR4 model integrations for the period of 2000-99. Filled and open circles denote AR4 models with and without prescribed ozone recovery, respectively. Color code is same to one in Fig. 6, and correlation coefficients are calculated by using all AR4 models.

integrations (Fig. 7f), UT temperature trends are relatively stronger in the integrations with ozone recovery, although the reason for this is unclear (filled circles in Fig. 7c, see also Fig. 8c).

We next compare $\left\langle P_{\mathrm{TP}}\right\rangle$ trends between $\mathrm{CCM}$ and IPCC AR4 model integrations (black versus red thick lines in Fig. 6). The global $\left\langle P_{\mathrm{TP}}\right\rangle$ trends predicted by the AR4 models are generally stronger than those in CCMs. This stronger trend primarily comes from the $\mathrm{SH}$, where $\left\langle P_{\mathrm{TP}}\right\rangle$ trends in the AR4 model integrations are much stronger than those in the CCM integrations (Fig. 6c). This difference in the two model sets is attributed to the different response of the LS temperature to climate change in each set. The multimodel mean temperature trends for all AR4 and CCM integrations are presented in Figs. 8a,d, respectively. Note how the temperature trends differ in the LS; this is true even when stratospheric ozone is prescribed in AR4 models (Fig. 8b). Figure 8e exhibits the difference in temperature trends between CCMs and AR4 models with prescribed ozone recovery. It can be seen that, while temperature tends in the troposphere are quantitatively the same, those in the stratosphere are substantially different. Given the wide range of variations in model physics, such similarity in the troposphere is remarkable and provides confidence that the difference in LS temperature trends seen in Fig. 8e is caused by stratospheric processes resolved by the CCMs.

The positive anomalies in the extratropical LS and negative anomalies in the tropical LS seen in Fig. 8e are qualitatively similar to ozone changes in the CCM integrations (Figs. 2d-f). This suggests that difference in LS temperature trends between CCM and AR4 model integrations might be associated with the prescribed ozone recovery in the AR4 models that is probably different from one in CCMs. However, a number of other factors might be also responsible for the difference in LS temperature trends. These include the absence of chemical transport, a poor vertical resolution, or a low model top in the AR4 models, which renders 

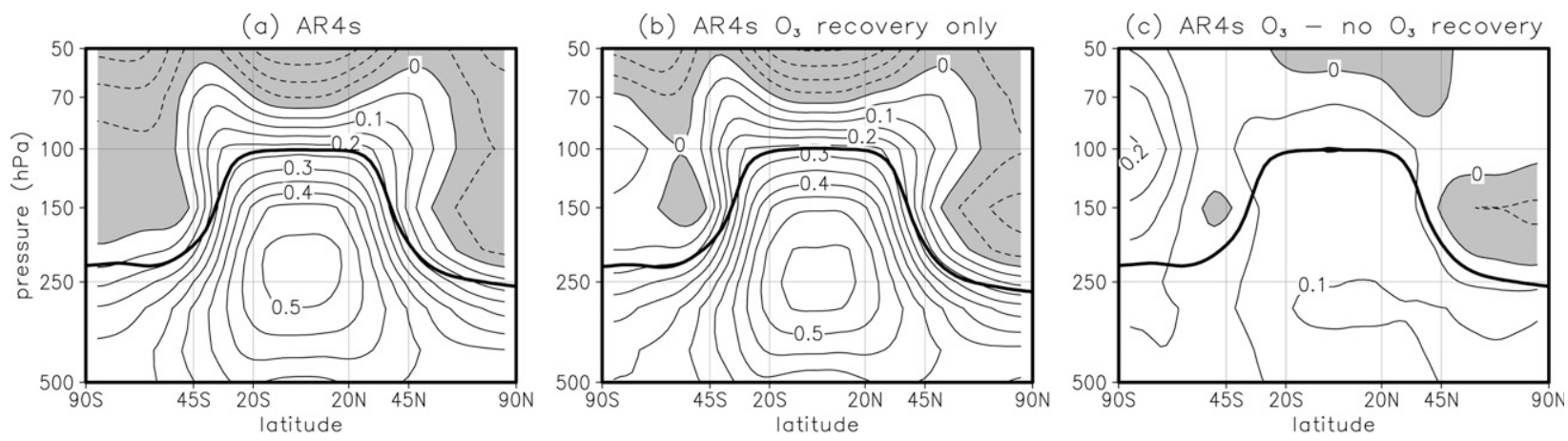

(d) $\mathrm{CCMs}$
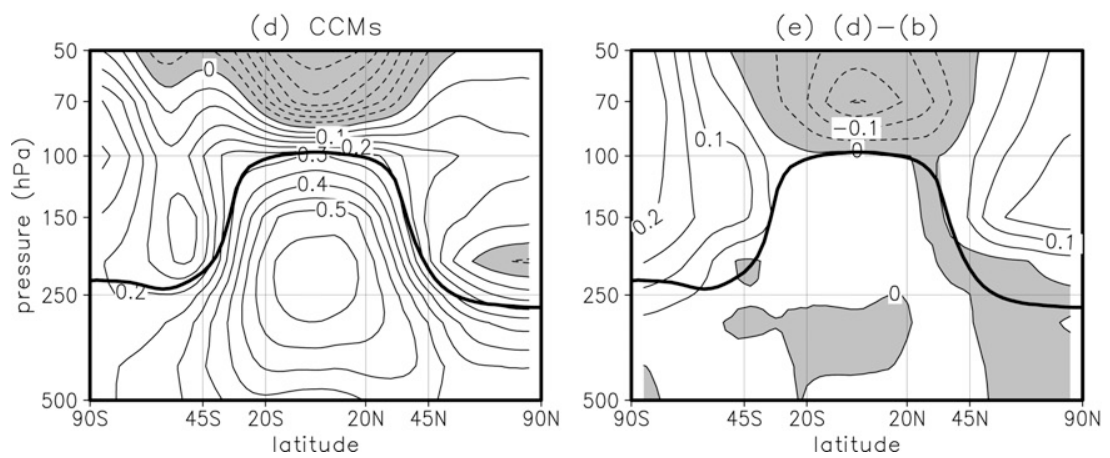

FIG. 8. Ensemble-mean trends of annual-mean zonal-mean temperature for the period of 2000-99: (a) all AR4 models, (b) AR4 models with prescribed ozone recovery, (c) difference between AR4 models with and without ozone recovery, (d) all CCMs, and (e) difference between all CCMs and AR4 models with prescribed ozone recovery. CIs are (a)-(d) 0.05 and (e) $0.025 \mathrm{~K}$ decade ${ }^{-1}$, and negative values are shaded. Thick solid lines show the ensemble-mean climatological tropopause in each model subset.

them unable to capture a realistic stratospheric circulation. In fact, a direct comparison between one of the CCMs (WACCM) and the corresponding AR4 model on which that CCM is based (CCSM3) shows that the difference in temperature trends is not entirely consistent with that in ozone trends (not shown). Further studies are needed to examine this issue.

The results in Fig. 8e provide an explanation for the difference in extratropical $\left\langle P_{\mathrm{TP}}\right\rangle$ trends between CCM and AR4 model integrations with prescribed ozone recovery (black and red solid lines in Fig. 6). In both hemispheres, LS cooling in the extratropics is weaker in the CCM integrations. This leads to weaker $\left\langle P_{\mathrm{TP}}\right\rangle$ trends (Figs. 6c,d). A noticeably different temperature trend is also found in the tropics. However, it does not accompany a visible difference in $\left\langle P_{\mathrm{TP}}\right\rangle$ trend between the two model sets (Fig. 6b). This weak sensitivity is partially due to the fact that the tropical $\left\langle P_{\mathrm{TP}}\right\rangle$ trend is only weakly sensitive to the changes in LS temperature. In fact, in Figs. 3 and 7, the linear slope between $\left\langle P_{\mathrm{TP}}\right\rangle$ and LS temperature trends in the tropics (Figs. 3d, 7d) is much sharper than that in the extratropics (Figs. 3e, 7e). As suggested by Santer et al. (2003b), it may be related to the vertical structure of the temperature profile near the tropopause, which changes more abruptly in the tropics and thus is more difficult to modify.

\section{Discussion and conclusions}

The globally averaged tropopause pressure $\left\langle P_{\mathrm{TP}}\right\rangle$ has been suggested as a sensitive indicator of anthropogenic climate change. Because of the combined effect of tropospheric warming by greenhouse gases and stratospheric cooling by ozone depletion, the global tropopause pressure (height) has been decreasing (increasing) over last two decades (Randel et al. 2000; Seidel et al. 2001; Sausen and Santer 2003; Santer et al. 2003a,b, 2004; Seidel and Randel 2006). Most of these studies have focused on the recent trend of $\left\langle P_{\mathrm{TP}}\right\rangle$, whereas $\left\langle P_{\mathrm{TP}}\right\rangle$ in the future has received little attention, partly because of the poorly resolved stratosphere in the GCMs that have been used to simulate future climate change. Although a few studies based on IPCC AR4-type GCM integrations have suggested that $\left\langle P_{\mathrm{TP}}\right\rangle$ would decreases linearly even in the twenty-first century (Sausen and Santer 2003; Santer et al. 2003b), this result is open to question because stratospheric processes, such as ozone chemistry, were not taken into account. In this study we have examined $\left\langle P_{\mathrm{TP}}\right\rangle$ trends, in the recent past and the future, with stratosphere-resolving chemistry climate models (CCMs), in which vertical resolution near the UT/LS is higher than conventional GCMs and stratospheric chemistry is fully interactive. 
All CCMs successfully reproduce the recent trend in $\left\langle P_{\mathrm{TP}}\right\rangle$. A relatively weak change in tropical $\left\langle P_{\mathrm{TP}}\right\rangle$ and a strong change in extratropical $\left\langle P_{\mathrm{TP}}\right\rangle$ are also well captured by the CCMs. For the future, it is found that $\left\langle P_{\mathrm{TP}}\right\rangle$ continues to decrease at all latitudes in the CCM integrations, primarily because of an overall warming in the UT. However, its trend is much weaker than that of the recent past. In particular, the rate of global $\left\langle P_{\mathrm{TP}}\right\rangle$ change in the first half of the twenty-first century is only half of that in the last two decades. This trend is noticeably different from the one reported in previous studies and the one in IPCC AR4 model integrations, which predicted essentially no changes in $\left\langle P_{\mathrm{TP}}\right\rangle$ trend from the twentieth to twenty-first centuries.

The reduction in future $\left\langle P_{\mathrm{TP}}\right\rangle$ trend in the $\mathrm{CCM}$ integrations is found to be linked to the LS temperature trend. All CCMs show recovery of extratropical $\mathrm{O}_{3}$, particularly in the SH (Eyring et al. 2007). This recovery leads to LS warming, which in turn reduces the $\left\langle P_{\mathrm{TP}}\right\rangle$ trend. The importance of stratospheric processes is further clarified by comparing the CCM results to those from the IPCC AR4 model integrations. Lacking a realistic representation of stratospheric processes, global $\left\langle P_{\mathrm{TP}}\right\rangle$ trends in the AR4 model integrations are larger than those in the CCM integrations, even when ozone recovery is prescribed. Although the SH LS experiences warming in those model integrations, it is weaker and broader than that found in CCM integrations. Further studies are needed to clarify why AR4 models underestimate SH LS warming even if stratospheric ozone recovery is prescribed, but this discrepancy suggests that the details of stratospheric processes are important to estimate $\left\langle P_{\mathrm{TP}}\right\rangle$ and LS temperature trends reliably. It also suggests that $\left\langle P_{\mathrm{TP}}\right\rangle$ trends estimated from AR4 model integrations might be unreliable as a climate change indicator.

The findings of this study have strong implications for the circulation change in the SH. The AR4 model integrations predict that the westerly jets in the future may shift poleward in both Hemispheres (Yin 2005; Miller et al. 2006; Lorenz and DeWeaver 2007). Together with this jet movement, eddy activity and storm tracks are expected to be strengthened at the poleward side of the climatological jet. While these circulation changes may be associated with changes in the nearsurface baroclinicity (Kushner et al. 2001; Son and Lee 2006), it is also possible that they may be affected by the changes of LS temperature or $\left\langle P_{\mathrm{TP}}\right\rangle$, as indicated by the studies of Haigh et al. (2005), Williams (2006), and Lorenz and DeWeaver (2007). Using idealized GCMs, these studies have shown that a decrease (increase) of tropopause pressure (height), by cooling the stratosphere, leads to a poleward shift in westerly jet. In view of this, we examined the future trend of $\mathrm{SH}$ westerly jet in the CCM integrations. Because of ozone-induced warming in the LS, one may expect somewhat different trends of $\mathrm{SH}$ westerly jet in the CCM integrations. In fact, the CCMs predict that the $\mathrm{SH}$ summer westerly jet will be decelerated on the poleward side of the climatological jet during the first half of the twentyfirst century, in stark contrast to the ensemble mean of AR4 model integrations (Son et al. 2008).

In sum, the results presented in this paper show that stratospheric processes are able to substantially affect the tropopause pressure trend and this, in turn, might affect important aspects of the tropospheric circulation. Hence, as recently suggested by Baldwin et al. (2007), a better representation of stratospheric physics and dynamics is likely to be an important challenge for the next round of IPCC model integrations.

Acknowledgments. We are most grateful to Drs. Veronika Eyring, Eugene Cordero, and Theodore Shepherd for helpful comments and GFDL AMTRAC, NIES CCSR, NASA GSFC GEOSCCM, PMOD/ ETHZ SOCOL, NCAR WACCM, and MSC/ University of Toronto/York University CMAM modeling groups for model outputs. We thank the NOAA and Climate Diagnostics Center for providing us with the NCEP-NCAR reanalysis dataset, and the NCAR for providing free access to ERA-40 data that are originally generated by ECMWF. We acknowledge the international modeling groups for providing their data for analysis. We thank the WCRP-SPARC CCMVal project for organizing the CCM data analysis activity, and the British Atmospheric Data Center (BADC) for collecting and archiving the CCM output. We also thank the Program for Climate Model Diagnosis and Intercomparison (PCMDI) for collecting and archiving the IPCC AR4 model data, the JSC/CLIVAR Working Groups on Coupled Modeling (WGCM) and their Coupled Model Intercomparison Project (CMIP) and Climate Simulation Panel for organizing the model data analysis activity, and the IPCC WG1 TSU for technical support. The IPCC Data Archive at Lawrence Livermore National Laboratory is supported by the Office of Sciences, U.S. Department of Energy. The work of SWS and LMP is supported by a grant from the U.S. National Science Foundation to Columbia University.

\section{REFERENCES}

Akiyoshi, H., T. Sugita, H. Kanzawa, and N. Kawamoto, 2004: Ozone perturbations in the Arctic summer lower stratosphere as a reflection of NOx chemistry and planetary scale 
wave activity. J. Geophys. Res., 109, D03304, doi:10.1029/ 2003JD003632.

Andrews, D. G., J. R. Holton, and C. B. Leovy, 1987: Middle Atmosphere Dynamics. Academic Press, 489 pp.

Austin, J., and F. Li, 2006: On the relationship between the strength of the Brewer-Dobson circulation and the age of stratospheric air. Geophys. Res. Lett., 33, L17807, doi:10.1029/2006GL026867.

-, and Coauthors, 2003: Uncertainties and assessments of chemistry-climate models of the stratosphere. Atmos. Chem. Phys., 3, 1-27.

—, R. J. Wilson, F. Li, and H. Vomel, 2006: Evolution of water vapor concentrations and stratospheric age of air in coupled chemistry-climate model simulations. J. Atmos. Sci., 64, 905-921.

Baldwin, M. P., M. Dameris, and T. G. Shepherd, 2007: How will the stratosphere affect climate change? Science, 316, 15761577.

Beagley, S. R., J. de Grandpre, J. N. Koshyk, N. A. McFarlane, and T. G. Shepherd, 1997: Radiative-dynamical climatology of the first generation Canadian Middle Atmosphere Model. Atmos.-Ocean, 35, 293-331.

Bromwich, D. H., and R. L. Fogt, 2004: Strong trends in the skill of the ERA-40 and NCEP-NCAR reanalysis in the high and midlatitudes of the Southern Hemisphere, 1958-2001. J. Climate, 17, 4603-4619.

Cordero, E. C., and P. M. de F. Forster, 2006: Stratospheric variability and trends in models used for the IPCC AR4. Atmos. Chem. Phys., 6, 5369-5380.

de Grandpré, J., S. R. Beagley, V. I. Fomichev, E. Griffioen, J. C. McConnell, A. S. Medvedev, and T. G. Shepherd, 2000: Ozone climatology using interactive chemistry: Results from the Canadian Middle Atmosphere Model. J. Geophys. Res., 105, 26 475-26 492.

Egorova, T., E. Rozanov, V. Zubov, E. Manzini, W. Schmutz, and T. Peter, 2005: Chemistry-climate model SOCOL: A validation of the present-day climatology. Atmos. Chem. Phys., 5, $1557-1576$.

Eyring, V., and Coauthors, 2006: Assessment of temperatures, trace species, and ozone in chemistry-climate model simulations of the recent past. J. Geophys. Res., 111, D22308, doi:10.1029/2006JD007327.

— spheric ozone in the 21st century. J. Geophys. Res., 112, D16303, doi:10.1029/2006JD008332.

Garcia, R. R., D. R. Marsh, D. E. Kinnison, B. A. Boville, and F. Sassi, 2007: Simulation of secular trends in the middle atmosphere, 1950-2003. J. Geophys. Res., 112, D09301, doi:10.1029/2006JD007485.

Gettelman, A., and Coauthors, 2008: The tropical tropopause layer 1960-2100. Atmos. Chem. Phys. Discuss., 8, 1367-1413.

Haigh, J. D., M. Blackburn, and R. Day, 2005: The response of tropospheric circulation to perturbations in lower-stratospheric temperature. J. Climate, 18, 3672-3685.

Haynes, P., J. Scinocca, and M. Greenslade, 2001: Formation and maintenance of the extratropical tropopause by baroclinic eddies. Geophys. Res. Lett., 28, 4179-4182.

Held, I. M., 1982: On the height of the tropopause and the static stability of the tropopause. J. Atmos. Sci., 39, 412-417.

Highwood, E. J., and B. J. Hoskins, 1998: The tropical tropopause. Quart. J. Roy. Meteor. Soc., 124, 1579-1604.

,-- , and P. Berrisford, 2000: Properties of the Arctic tropopause. Quart. J. Roy. Meteor. Soc., 126, 1515-1532.

Hoerling, M. P., T. D. Schaack, and A. J. Lenzen, 1991: Global objective tropopause analysis. Mon. Wea. Rev., 119, 1816-1831.
Hoinka, K. P., 1998: Statistics of the global tropopause pressure. Mon. Wea. Rev., 126, 2248-2265.

Holton, J. R., P. H. Haynes, M. E. McIntyre, A. R. Douglass, R. B. Rood, and L. Pfister, 1995: Stratosphere-troposphere exchange. Rev. Geophys., 33, 403-439.

Houghton, J. T., Y. Ding, D. J. Griggs, M. Noguer, P. J. van der Linden, and D. Xiaosu, Eds., 2001: Climate Change 2001: The Scientific Basis. Cambridge University Press, 944 pp.

Jiang, X., S. J. Eichelberger, D. L. Hartmann, R. Shia, and Y. L. Yung, 2007: Influence of doubled $\mathrm{CO}_{2}$ on ozone via changes in the Brewer-Dobson circulation. J. Atmos. Sci., 64, 2751-2755.

Johns, T. C., and Coauthors, 2006: The new Hadley Centre climate model HadGEM1: Evaluation of coupled simulations. J. Climate, 19, 1327-1353.

Ko, M. K. W., N. Sze, and D. K. Weisenstein, 1989: The roles of dynamical and chemical processes in determining the stratospheric concentration of ozone in one-dimensional and twodimensional models. J. Geophys. Res., 94, 9889-9896.

Kurokawa, J., H. Akiyoshi, T. Nagashima, H. Masunaga, T. Nakajima, M. Takahashi, and H. Nakane, 2005: Effects of atmospheric sphericity on stratospheric chemistry and dynamics over Antarctica. J. Geophys. Res., 110, D21305, doi:10.1029/2005JD005798.

Kushner, P. J., I. M. Held, and T. L. Delworth, 2001: Southern Hemisphere atmospheric circulation response to global warming. J. Climate, 14, 2238-2249.

Lorenz, D. J., and E. T. DeWeaver, 2007: Tropopause height and zonal wind response to global warming in the IPCC scenario integrations. J. Geophys. Res., 112, D10119, doi:10.1029/ 2006JD008087.

Manabe, S., and R. F. Strickler, 1964: Thermal equilibrium of the atmosphere with a convective adjustment. J. Atmos. Sci., 21, 361-385.

Meehl, G. A., and Coauthors, 2007: Global climate projections. Climate Change 2007: The Physical Sciences Basis, S. Solomon et al., Eds., Cambridge University Press, 747-845.

Miller, R. L., G. A. Schmidt, and D. T. Shindell, 2006: Forced annular variations in the 20th century Intergovernmental Panel on Climate Change Fourth Assessment Report models. J. Geophys. Res., 111, D18101, doi:10.1029/2005JD006323.

Nakicenovic, N., and R. Swart, Eds., 2000: Emissions Scenarios. Cambridge University Press, 599 pp.

Randall, D. A., and Coauthors, 2007: Climate models and their evaluation. Climate Change 2007: The Physical Science Basis, S. Solomon et al., Eds., Cambridge University Press, 589-662.

Randel, W. J., F. Wu, and D. Gaffen, 2000: Interannual variability of the tropical tropopause derived from radiosonde and NCEP reanalysis. J. Geophys. Res., 105, 15 509-15 523.

Reichler, T., M. Dameris, and R. Sausen, 2003: Determining the tropopause height from gridded data. Geophys. Res. Lett., 30, 2042, doi:10.1029/2003GL018240.

Rozanov, E., and Coauthors, 2005: Assessment of the ozone and temperature variability during 1979-1993 with the chemistryclimate model SOCOL. Adv. Space Res., 35, 1375-1384.

Santer, B. D., and Coauthors, 2000: Statistical significance of trends and trend differences in layer-average atmospheric temperature time series. J. Geophys. Res., 105, 7337-7356.

_ , and Coauthors, 2003a: Contribution of anthropogenic and natural forcing to recent tropopause height changes. Science, 301, 479-483.

— , and Coauthors, 2003b: Behavior of tropopause height and atmospheric temperature in models, reanalysis, and observa- 
tions: Decadal changes. J. Geophys. Res., 108, 4002, doi:10.1029/2002JD002258.

- , and Coauthors, 2004: Identification of anthropogenic climate change using a second-generation reanalysis. J. Geophys. Res., 109, D21104, doi:10.1029/2004JD005075.

Sausen, R., and B. D. Santer, 2003: Use of changes in tropopause height to detect human influences on climate. Meteor. Z., 12, 131-136.

Schneider, T., 2004: The tropopause and the thermal stratification in the extratropics of a dry atmosphere. J. Atmos. Sci., 61, 1317-1340.

Seidel, D. J., and W. J. Randel, 2006: Variability and trends in the global tropopause estimated from radiosonde data. J. Geophys. Res., 111, D21101, doi:10.1029/2006JD007363.

_ _ R. J. Ross, J. K. Angell, and G. C. Reid, 2001: Climatological characteristics of the tropical tropopause as revealed by radiosondes. J. Geophys. Res., 106, 7857-7878.

Son, S.-W., and S. Lee, 2006: Preferred modes of variability and their relationship with climate change. J. Climate, 19, $2063-$ 2075.

,$- \ldots$, and S. B. Feldstein, 2007: Intraseasonal variability of the zonal-mean extratropical tropopause height. J. Atmos. Sci., 64, 608-620.

_- and Coauthors, 2008: Impact of stratospheric ozone recovery on the Southern Hemisphere westerly jet. Science, 320 , 1486-1489.

Steinbrecht, W., H. Claude, V. Koehler, and K. Hoinka, 1998: Correlation between tropopause height and total ozone: Im- plication for long-term changes. J. Geophys. Res., 103, $19183-$ 19192.

Stolarski, R. S., A. R. Douglass, S. Steenrod, and S. Pawson, 2006: Trends in stratospheric ozone: Lessons learned from a 3D chemical transport model. J. Atmos. Sci., 63, 1028-1041.

Thuburn, J., and G. C. Craig, 2000: Stratospheric influence on tropopause height: The radiative constraint. J. Atmos. Sci., 57, 17-28.

Williams, G. P., 2006: Circulation sensitivity to tropopause height. J. Atmos. Sci., 63, 1954-1961.

WMO, 1957: Definition of the tropopause. WMO Bull., 6, 136.

, 1986: Atmospheric ozone 1985: Global ozone research and monitoring report. WMO Rep. 16, 392 pp.

WMO/UNEP, 2003: Scientific Assessment of Ozone Depletion: 2002. WMO Global Ozone Research and Monitoring Project Rep. 47.

Wong, S., and W.-C. Wang, 2003: Tropical-extratropical connection in interannual variation of the tropopause: Comparison between NCEP/NCAR reanalysis and an atmospheric general circulation model simulation. J. Geophys. Res., 108, 4043, doi:10.1029/2001JD002016.

Yin, J. H., 2005: A consistent poleward shift of the storm tracks in simulations of 21st century climate. Geophys. Res. Lett., 32, L18701, doi:10.1029/2005GL023684.

Yulaeva, E., J. R. Holton, and J. M. Wallace, 1994: On the cause of the annual cycle in tropical lower stratospheric temperature. J. Atmos. Sci., 51, 169-174. 